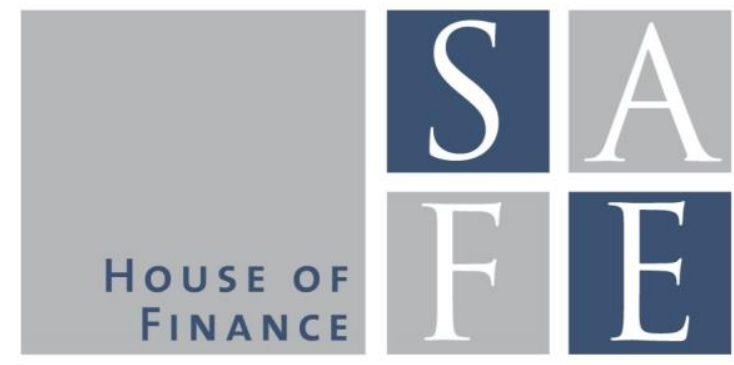

WORKING PAPER SERIES

Michael Donadelli - Patrick Grüning - Marcus Jüppner - Renatas Kizys

\title{
Global Temperature, R\&D Expenditure, and Growth
}

SAFE Working Paper No. 188

SAFE I Sustainable Architecture for Finance in Europe A cooperation of the Center for Financial Studies and Goethe University Frankfurt 


\section{Non-Technical Summary}

Climate change and global warming are critical developments and are inevitably shaping the global economy and society. Population health, agricultural value added, infrastructure, productivity - to mention just few spheres - are all affected by climatic conditions, albeit to a varying extent. The agenda of academic and international policy debate is dominated by two fundamental questions. First, what are the long-term consequences of global warming on the economy and society? Second, how could the economy and society adapt to global warming in the least disruptive way?

In terms of the first question, there is a widespread belief that climate change poses major challenges and risks to global economic activity. Specifically, our empirical exercise shows that positive temperature shocks lead to a reduction in the growth rate of business R\&D expenditure, which ranges from 0.6 to 0.84 percentage points in the $G 7$ countries. We subsequently develop a general equilibrium model that accounts for this empirical finding. Particularly, we assume that temperature shocks have a negative influence on the accumulation of patents. Therefore, climate change has disruptive effects on economic activity by increasing the patent obsolescence rate, which in turn places a constraint on the growth rate of the economy. We further show that temperature shocks are associated with declining welfare. Under a plausible scenario, a positive temperature shock manifests in an $11 \%$ decrease of welfare in the long run.

This study also delves into the second question that is concerned about the optimal economic policy response. Our results indicate that governments need to spend $22.2 \%$ of their budgets as capital investment subsidy in order to fully compensate for the welfare costs caused by global temperature risk. The benchmark case scenario is then extended to cater to a broad range of different eventualities and to vindicate our qualitative research findings. How such government spending ought to be structured is left for future research. Taken together, our findings indicate that governments need to incorporate the stylized temperature change, output, and welfare nexus into the governments' objective function and that governments should fight the adverse consequences of global warming rather aggressively. 


\title{
Global Temperature, R\&D Expenditure, and Growth
}

\author{
Michael Donadelli $^{*} \quad$ Patrick Grüning ${ }^{* *} \quad$ Marcus Jüppner ${ }^{* * *} \quad$ Renatas Kizys ${ }^{* * * *}$
}

This version: November 15, 2017

\begin{abstract}
We shed new light on the macroeconomic effects of rising temperatures. In the data, a shock to global temperature dampens expenditures in research and development $(\mathrm{R} \& \mathrm{D})$. We rationalize this empirical evidence within a stochastic endogenous growth model, featuring temperature risk and growth sustained through innovations. In line with the novel evidence in the data, temperature shocks undermine economic growth via a drop in $\mathrm{R} \& \mathrm{D}$. Moreover, in our endogenous growth setting temperature risk generates non-negligible welfare costs (i.e., $11 \%$ of lifetime utility). An active government, which is committed to a zero fiscal deficit policy, can offset the welfare costs of global temperature risk by subsidizing the aggregate capital investment with one-fifth of total public spending.
\end{abstract}

Keywords: Global Temperature, R\&D, Welfare Costs

JEL: E30, G12, Q00

\footnotetext{
*Faculty of Economics and Business Administration and Research Center SAFE, Goethe University Frankfurt, House of Finance, Theodor-W.-Adorno Platz 3, 60629 Frankfurt am Main, Germany. E-mail: michael.donadelli@gmail.com.

${ }^{* *}$ Center for Excellence in Finance and Economic Research (CEFER), Bank of Lithuania, and Faculty of Economics, Vilnius University. Address: Totoriu g. 4, 01121 Vilnius, Lithuania. E-mail: PGruening@lb.lt.

${ }^{* * *}$ Deutsche Bundesbank, and Faculty of Economics and Business Administration, Goethe University Frankfurt. Address: Wilhelm-Epstein-Straße 14, 60431 Frankfurt am Main, Germany. E-mail: marcus.jueppner@bundesbank.de.

${ }^{* * * *}$ Faculty of Business and Law, University of Portsmouth, Richmond Building, Portland Street, Portsmouth PO1 3DE, United Kingdom. E-mail: renatas.kizys@port.ac.uk.

We would like to thank the seminar participants at the 1st Sports and Environmental Economics Days (SEED) Workshop for helpful comments. We gratefully acknowledge research and financial support from the Research Center SAFE, funded by the State of Hessen initiative for research LOEWE. The views expressed herein are solely those of the authors and do not necessarily reflect the views of the Bank of Lithuania, the Bundesbank, or the Eurosystem. All remaining errors are our own.
} 


\section{Introduction}

Rising global temperature has spawned intense academic and international policy debate, and has highlighted the limits to sustainability of the global economy. Whilst economists and policy makers generally agree that climate change can generate huge costs on the economy and society, there is no consensus on i) the mechanism through which such costs originate, ii) the industries, which are likely to be mostly affected by rising temperatures, and iii) the scale of such costs. Further on the mechanism of the climate change effects, in a speech on the global warmingfinancial stability nexus at Lloyd's of London, Mark Carney, the governor of the Bank of England, underscored three broad channels that involved physical risks, liability risks, and transition risks. ${ }^{1}$ The latter refers to financial risks resulting from the process of adjustment towards a lower-carbon economy and triggering a revaluation of assets.

Against this background, our research contributes to the related literature in two remarkable ways. First, we provide novel empirical evidence on the effects of temperature shocks on the macroeconomy. We extend previous empirical studies (e.g. Colacito, Hoffmann, and Phan, 2016) by investigating the effects of temperature increases on $R \& D$ expenditures, a channel that has not been investigated yet. Using data for the G7 and OECD countries, we find that a rise in global temperature undermines growth in $\mathrm{R} \& \mathrm{D}$ investments in a strong and persistent way. Second, given our empirical results, it is straightforward to model climate risk in a framework where technical progress is endogenous. More specifically, we introduce temperature dynamics as modeled in Bansal and Ochoa (2011b) into an endogenous growth model in the spirit of Kung and Schmid (2015) where temperature shocks negatively affect R\&D investments. In our novel stochastic endogenous growth model, we find that temperature risk produces sizable welfare costs (i.e., $11 \%$ of lifetime consumption) that can be offset by subsidizing capital investment with around $22 \%$ of total government expenditures. ${ }^{2}$ Global temperature shocks reduce long-run growth perspectives in our model as they are assumed to harm the accumulation of patents, which drives down long-run productivity. Furthermore, our research may contribute to environmental, fiscal, and social policy advice. Specifically, our research findings indicate that environmental degradation makes $R \& D$ patents obsolete at an increasing rate, which translates into a significant

\footnotetext{
${ }^{1}$ http://www.bankofengland.co.uk/publications/Pages/speeches/2015/844.aspx.

${ }^{2}$ Similarly, the need of investment in physical capital is also emphasized in Angelopoulos, Economides, and Philippopoulos (2013), who find that environmental uncertainty leads to an increase in investment through precautionary behavior, ultimately leading to an improvement in welfare.
} 
welfare burden in the long run. One way to prevent or alleviate such a burden would be to incorporate the stylized temperature change, output, and welfare nexus into the government's objective function.

The remainder of this paper is structured as follows. In Section 2, we review the related literature. Section 3 documents the novel empirical facts regarding the effects temperature shocks on R\&D. In Section 4, we present the general equilibrium model. Sections 5 and 6 present our benchmark calibration and the quantitative results, respectively. Three important robustness checks are relegated to Section 7. Finally, Section 8 provides concluding remarks.

\section{Related Literature}

Empirically, our paper fits into a growing literature that explores the implications of rising temperatures for real economic activity. Bansal and Ochoa (2011b), for instance, find that a global temperature shock (i.e., a rise in temperature of $0.2^{\circ} \mathrm{C}$ ) reduces world consumption growth by 0.2 percentage points (pp). They also observe that this effect lasts for several years. Dell, Jones, and Olken (2012) find that higher temperatures substantially reduce economic growth in poor countries while Deryugina and Hsiang (2014) find that an increase in daily average temperature above $15^{\circ} \mathrm{C}$ is associated with a substantial reduction in U.S. personal income. Still focusing on the U.S., Colacito, Hoffmann, and Phan (2016) show that a $1^{\circ} \mathrm{F}$ increase in average summer temperature produces a reduction in output growth of (around) 0.2pp. Du, Zhao, and Huang (2017) observe that a rise in long-run temperature undermines output growth not only in the U.S. but also in the euro area. We extend these studies by examining the effects of rising temperatures on $\mathrm{R} \& \mathrm{D}$ expenditure.

From a quantitative point of view, our research seeks to shed light on the theoretical channels of the stylized negative income effect of temperature increases. In this respect, we are connected to the strand of literature that integrates environmental economics with macroeconomics and focuses on the effects of environmental degradation on the economy. Prominent in this strand are studies that embed environmental policy and temperature dynamics in real business cycle (RBC) models. Fischer and Springborn (2011) and Heutel (2012), for instance, investigate how optimal climate policies should be designed under stochastic productivity shocks. Bansal and Ochoa (2011b) propose an augmented long-run risk model in which temperature negatively 
impacts long-run growth. Specifically, the model captures the long-lasting effect that global temperature has on world consumption growth observed in the data. Based on the empirical evidence that temperature shocks undermine TFP growth, Donadelli, Jüppner, Riedel, and Schlag (2017), following the approach of Bansal and Ochoa (2011b), integrate U.S. temperature dynamics into a production-based model featuring recursive preferences, long-run productivity risk, and investment adjustment costs. We differ from these theoretical approaches aiming at studying the macroeconomic effects of climate change-related phenomena in that we analyze the welfare implications of rising temperatures within a stochastic endogenous growth framework. This is done to be in line with our novel empirical evidence showing that rises in temperature level directly affect $\mathrm{R} \& \mathrm{D}$ expenditure (i.e., the most productive sector of the economy).

More closely related to us are thus studies modeling climate effects in an endogenous growth setting. Using different standard models, Fankhauser and Tol (2005) analyze the effects of climate change on capital accumulation and saving. van der Zwaan, Gerlagh, Klaassen, and Schrattenholzer (2002) find that introducing endogenous technological change affects optimal climate policies and the path of emission reduction. ${ }^{3}$ The work of Dietz and Stern (2015) constitutes a recent contribution in this field. In line with empirical evidence (e.g., Dell, Jones, and Olken, 2012), they specify climate change to affect long-run growth. Moreover, they introduce climate risk and allow the damage of global warming to increase rapidly at some temperature to reflect catastrophic climate damages after a certain degree of heating. In contrast to the standard literature on so-called integrated assessment models (IAM) (e.g., Nordhaus, 2008), the framework of Dietz and Stern (2015) requires optimal emission cuts to be strong. Our modeling approach is novel in the sense that we combine all the ingredients mentioned above, i.e., climate risk, stochastic productivity, and long-run growth effects of temperature increases via the effect on $R \& D$.

Another stream of literature concentrates on New Keynesian (NK) dynamic general equilibrium models that embody pollutant emissions and the design of environmental policy. One example is Annicchiarico and Di Dio (2015), in which the performance of alternative environmental policy rules under real and nominal uncertainty, as well as the interaction between environmental and monetary policy are studied. In a similar vein, Annicchiarico and Di Dio (2017) investigate the optimal monetary and environmental policy mix. They show that the optimal

\footnotetext{
${ }^{3} \mathrm{~A}$ literature review on climate policy analysis under endogenous technological progress is provided by Gillingham, Newell, and Pizer (2008).
} 
policy design depends on the intensity of the distortions the policy makers have to address, the instruments they have available, and the way they interact. Differently from Annicchiarico and Di Dio (2015) who assume a closed economy, Ganelli and Tervala (2011) evaluate the degree to which environmental policy shocks can be transmitted internationally within a fully-fledged open economy New Keynesian model. Furthermore, while in Annicchiarico and Di Dio (2015) the stock of pollutant undermines productivity of firms, key to the model developed by Ganelli and Tervala (2011) is a productivity enhancing factor that includes both the quality of the environment and the flow of polluting emissions. Broadly speaking, we differ from this analysis in at least two main aspects. First, we abstract from finding optimal policies. Second, as in many other studies, we focus exclusively on global temperature dynamics as a proxy for climate change.

\section{The Facts}

Recent studies document that rising temperatures may have sizable adverse effects on economic activity. Using a novel dataset on private and public R\&D expenditure provided by the OECD Main Science and Technology Indicators, we shed new light on the macroeconomic effects of rising temperatures. Specifically, by means of standard empirical methodologies, we study the impact of global temperature shocks on aggregate expenditures in $R \& D$. The main results of this analysis are reported in Figure 1 and Table I and discussed in what follows.

Bivariate VAR analysis. In the spirit of Bansal and Ochoa (2011b), we first estimate a bivariate VAR model of G7 Business Enterprise Expenditure in R\&D (BERD) growth and global temperature. ${ }^{4}$ The impulse response is depicted in Figure 1 (Panel A) and shows that a shock in global temperature reduces G7 private R\&D spending by $0.6 \mathrm{pp}$. The impact is quite persistent lasting for 10 years. For robustness, we replicate our simple VAR analysis by using (i) BERD growth data for the whole OECD group (Panel B) and (ii) data on Gross Domestic Expenditure on R\&D (GERD), which accounts for both business enterprise and government R\&D spending (Panels $\mathrm{C}$ and $\mathrm{D})$. These additional tests confirm that a global temperature shock negatively affect both private and public productive spending in major advanced economies. ${ }^{5}$

\footnotetext{
${ }^{4}$ Let us stress that all the R\&D growth series are stationary and global temperature is trend stationary.

${ }^{5}$ For the sake of robustness, we have also estimated a bi-variate VAR of R\&D expenditure and global temperature growth. A shock to global temperature growth produces a drop on R\&D of similar size.
} 
Figure 1: Impulse Response of R\&D Expenditure Growth to Global TemPERATURE
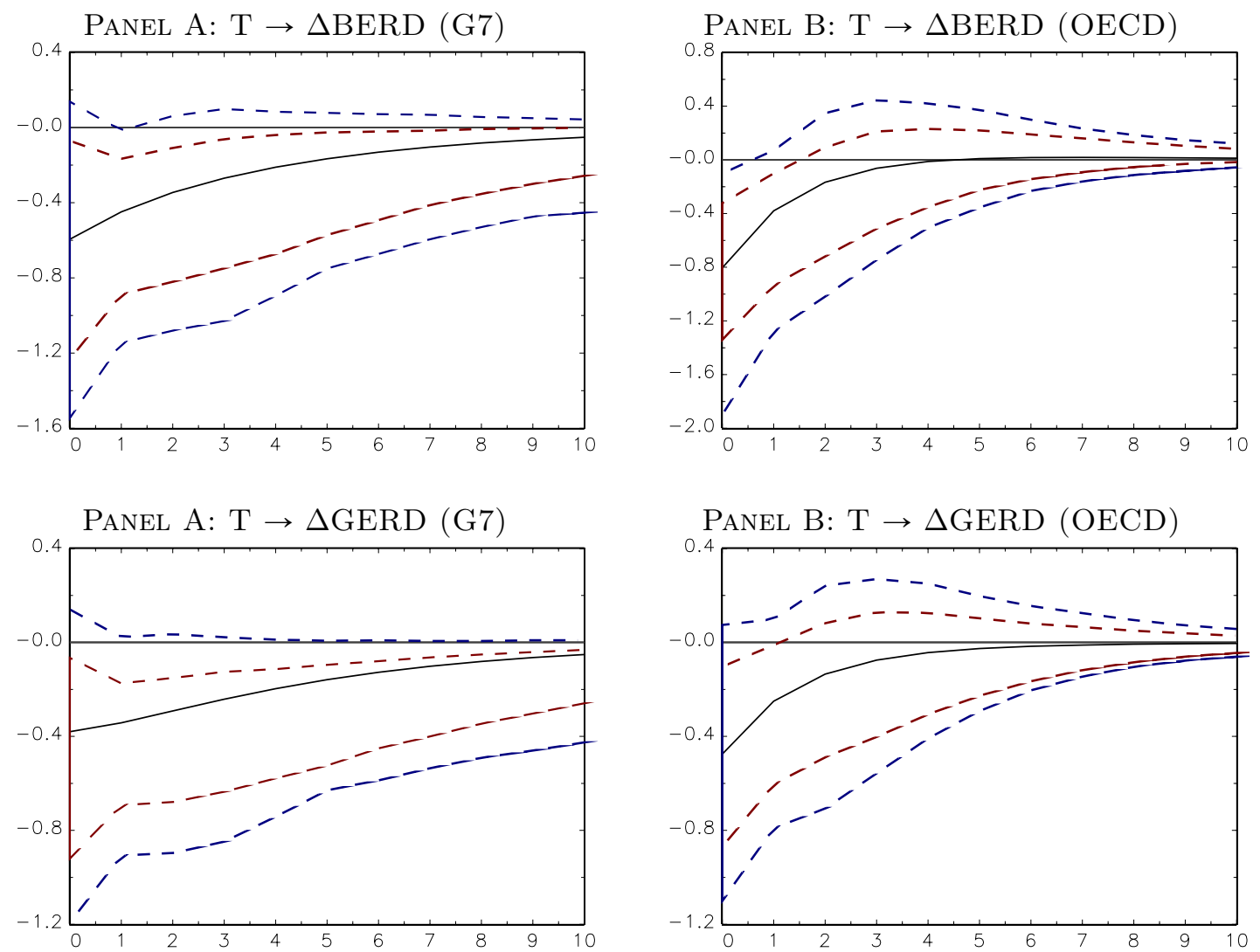

Notes: This figure presents Cholesky orthogonalized impulse responses of R\&D growth to a global temperature shock. Impulse responses are obtained by estimating a bi-variate VAR(1) where global temperature is ordered first. A constant is included. Solid black lines: estimated impulse responses. Dashed blue lines: 90\% bootstrapped confidence bands. Dashed red lines: $68 \%$ bootstrapped confidence bands. The growth rates of BERD and GERD for the G7 and OECD are from the OECD Main Science and Technology Indicators Database. Data on Global temperature (expressed in degrees Celsius) are from the Climate Research Unit. Data are annual and span the period from 1981 to 2015.

Dynamic panel regressions. In order to shed further robustness on the relationship between temperature increases and R\&D expenditures, we employ a dynamic panel regression with time-fixed effects in the spirit of Colacito, Hoffmann, and Phan (2016). As in our bi-variate VAR estimation we focus on both the G7 group and the whole OECD region. Specifically, we regress BERD and GERD growth in each country on its lagged value and temperature $(T)$ :

$$
\Delta R \& D_{i, t}^{j}=c_{i}+\rho \Delta R \& D_{i, t-1}^{j}+\beta T_{i, t}+\epsilon_{i, t}
$$

However, the effect is less persistent and less statistically significant. Impulse responses to a shock to global temperature growth are depicted in Figure B.2. To let results not rely on the variables ordering, in an additional robustness test, we have computed generalized impulse responses. These provide almost indistinguishable dynamics. For space considerations, they are not reported but available upon request by the authors. 
where $j \in\{B E R D, G E R D\}$. We have checked that these $\mathrm{R} \& \mathrm{D}$ expenditure growth rates are stationary using unit root tests. Hence, we do not need to test for a cointegration relationship between the variables in our panel regressions, since there cannot be one.

In a first step, we use global temperature as regressor and set $T_{i} \equiv T_{G}$. This specification is similar to the panel analysis of Bansal and Ochoa (2011a) who also use global temperature as regressor and makes results comparable to our VAR estimation. Moreover, we standardize the temperature series such that we can interpret the coefficient $\beta$ as the change in $R \& D$ expenditure growth (in pp) after a one standard deviation increase in global temperature. As a robustness check we follow Colacito, Hoffmann, and Phan (2016) and use country-specific temperature levels, $T_{i}$, in a second set of estimations.

Regression results for the G7 countries, the OECD countries, and the OECD plus additional countries $(\mathrm{OECD}+)$ are reported in Table I. Panel A reports estimation results using global temperature as regressor. Except for the OECD + countries using GERD as R\&D measure, temperature effects on $\mathrm{R} \& \mathrm{D}$ expenditure growth are always significantly negative, at least at the $5 \%$ level. The point estimates from the panel estimation are larger compared to those from the VAR estimation but lie within the confidence bands of the impulse responses depicted in Figure 1. Panel estimations also confirm that the effect of an increase in global temperature on R\&D expenditures is larger for the group of OECD countries than for the G7 group. ${ }^{6}$

In Panel B where we use country-specific temperature levels, temperature effects on R\&D expenditures are still found to be negative but at lower significance levels. However, performing a one-sided test with $H_{0}: \beta \geqslant 0$, temperature effects are found to significantly undermine (at the 10\% level) both BERD and GERD in the G7 and OECD countries. Given the prior evidence about the negative economic effects of rising temperatures, this test may be more reasonable and further corroborates our results when computing significance levels for the onesided test. ${ }^{7}$ Therefore, these additional results confirm that rising temperatures are associated with drops in R\&D expenditures. We suspect that panel estimates are more significant using global temperature because global warming effects can be best captured through increases in

\footnotetext{
${ }^{6}$ We acknowledge that our estimates from the fixed effects estimation are subject to a simultaneous equation bias from the endogeneity between the error term and the lagged dependent variable. To account for this, we perform the Hausman test by comparing the fixed effects estimates to the consistent estimates from a mean-group estimation. Results which are available upon request suggest that the simultaneous equation bias is minimal for these data.

${ }^{7}$ The $\mathrm{p}$-value for the test $H_{0}: \beta \geqslant 0$ is half of the one from the two-sided test reported in Table I, since the coefficients for temperature are all found to be negative.
} 
Table I: Effects of Rising Temperature on R\&D Expenditure

\begin{tabular}{|c|c|c|c|}
\hline \multicolumn{4}{|c|}{ Panel A: R\&D vs Global Temperature } \\
\hline & G7 & OECD & $\mathrm{OECD}+$ \\
\hline Regressor & $(1)$ & $(2)$ & $(3)$ \\
\hline$\triangle B E R D(-1)$ & $\begin{array}{c}0.36^{* * * *} \\
(0.000)\end{array}$ & $\begin{array}{c}0.06 \\
(0.538)\end{array}$ & $\begin{array}{c}0.09 \\
(0.338)\end{array}$ \\
\hline$T_{G}$ & $\begin{array}{c}-0.84^{* *} \\
(0.013)\end{array}$ & $\begin{array}{c}-2.27 * * * \\
(0.002)\end{array}$ & $\begin{array}{c}-1.74^{* *} \\
(0.016)\end{array}$ \\
\hline$\triangle G E R D(-1)$ & $\begin{array}{c}0.38^{* * *} \\
(0.000)\end{array}$ & $\begin{array}{c}0.18^{* * *} \\
(0.002)\end{array}$ & $\begin{array}{c}0.24^{* * *} \\
(0.000)\end{array}$ \\
\hline$T_{G}$ & $\begin{array}{c}-0.55^{* * *} \\
(0.005)\end{array}$ & $\begin{array}{c}-0.75^{* *} \\
(0.013)\end{array}$ & $\begin{array}{c}-0.41 \\
(0.263)\end{array}$ \\
\hline \multicolumn{4}{|c|}{ Panel B: R\&D vs Country-specific Temperature } \\
\hline & G7 & OECD & $\mathrm{OECD}+$ \\
\hline Regressor & $(1)$ & $(2)$ & $(3)$ \\
\hline$\triangle B E R D(-1)$ & $\begin{array}{c}0.40 * * * \\
(0.000)\end{array}$ & $\begin{array}{c}0.07 \\
(0.486)\end{array}$ & $\begin{array}{c}0.09 \\
(0.341)\end{array}$ \\
\hline$T_{i}$ & $\begin{array}{c}-0.40 \\
(0.124)\end{array}$ & $\begin{array}{c}-0.61 \\
(0.164) \\
\end{array}$ & $\begin{array}{c}-0.41 \\
(0.343)\end{array}$ \\
\hline$\triangle G E R D(-1)$ & $\begin{array}{c}0.40^{* * *} \\
(0.000)\end{array}$ & $\begin{array}{c}0.19^{* * *} \\
(0.002)\end{array}$ & $\begin{array}{l}0.23^{* * *} \\
(0.000)\end{array}$ \\
\hline$T_{i}$ & $\begin{array}{c}-0.34 \\
(0.148)\end{array}$ & $\begin{array}{l}-0.34 \\
(0.203)\end{array}$ & $\begin{array}{c}-0.14 \\
(0.619)\end{array}$ \\
\hline
\end{tabular}

Notes: This table presents predictability evidence for R\&D growth. Panel A reports the estimated coefficients on average annual temperature from a panel regression of BERD (GERD) growth rate, $\triangle B E R D_{i, t}\left(\Delta G E R D_{i, t}\right)$ on its lagged value and global temperature, $T_{G}$. Panel $\mathrm{B}$ report the estimated coefficients on average annual temperature from a panel regression of BERD (GERD) growth rate, $\triangle B E R D_{i, t}\left(\Delta G E R D_{i, t}\right)$ on its lagged value and country-specific temperature, $T_{i}$. In column (1), models are estimated on data for the G7 countries while in column (2) and (3) we use data for the full OECD group and all OECD members plus seven additional countries (Argentina, China, Romania, Russia, Singapore, South Africa, and Chinese Taipei), respectively. Robust standard errors are computed by clustering standard errors at the country level. The p-values are reported in round brackets. The growth rate of BERD (GERD) for the G7 and OECD are from the OECD Main Science and Technology Indicators Database. Data on Global temperature (expressed in degrees Celsius) are from the Climate Research Unit. Countries' annual average temperatures (expressed in degrees Celsius) are from the Climate Change Knowledge Portal (CCKP). Temperature data are not available for Romania and Chinese Taipei. The sample is $1981-2015{ }^{* * *}$ and ${ }^{* *}$ denote significance at the $1 \%$ and $5 \%$ level, respectively.

the global temperature level. It may be that in this case temperature fluctuations not related to climate change are averaged out to a greater extend compared to individual temperature series.

As an additional robustness test, we include a dummy variable capturing the effect of the global financial crisis on R\&D expenditures as it may be that the temperature effect is upward biased due to its potential (spurious) correlation with the business cycle unaccounted for in the empirical model. Results are reported in Appendix B, Table B.I. In this case, temperature effects are still found to be negative and significant. Moreover, if we divide the largest sample available $(\mathrm{OECD}+)$ into different country groups, we observe that the negative effects of rises in global temperature on $\mathrm{R} \& \mathrm{D}$ are larger for 1) developing countries compared to developed countries and 2) "warmer" countries compared to "cooler" countries (see Table B.II).

Taken together, our empirical results suggest that increases in global temperature harm expenditures in R\&D. Moreover, these adverse effects are found to be long-lasting. The next step is to rationalize these findings within an endogenous growth model featuring $R \& D$ dynamics to quantify the effects of temperature shocks on macroeconomic quantities, asset prices, and 
welfare.

\section{The Model}

In this section, we develop a stochastic endogenous growth model with a government sector featuring global temperature dynamics as in Bansal and Ochoa (2011b). We assume that temperature risk has an impact on the real economy via its contribution to the depreciation risk of patents. Our model allows us to reproduce the adverse effects of temperature shocks on R\&D expenditures, the real economy, and asset prices, as observed in the data.

Representative household. The representative household is equipped with Epstein and Zin (1989) preferences over the utility flow $u_{t}$ :

$$
U_{t}=\left[(1-\beta) u_{t}^{1-\frac{1}{\psi}}+\beta\left(\mathbb{E}_{t}\left[U_{t+1}^{1-\gamma}\right]\right)^{\frac{1-1 / \psi}{1-\gamma}}\right]^{\frac{1}{1-1 / \psi}}
$$

where $\gamma$ is relative risk aversion, $\psi$ determines the elasticity of intertemporal substitution, and $\beta$ is the time discount factor. The utility flow is given by:

$$
u_{t}=C_{t}\left(\bar{L}-L_{t}\right)^{\tau}
$$

where $C_{t}$ defines consumption of the final good, $\bar{L}-L_{t}$ represents leisure (total time endowment less labor supply), and $\tau$ determines the elasticity of labor supply. The budget constraint of the household reads:

$$
C_{t}=\left(1-\tau_{l, t}\right) W_{t}^{u} L_{t}+D_{a, t}-S_{t}
$$

where $W_{t}^{u}$ denotes the frictionless wage, $L_{t}$ is the amount of labor supplied by the household, $\tau_{l, t}$ is the time-varying labor income tax rate, $D_{a, t}$ is aggregate dividends, and $S_{t}$ is the economy's total R\&D investment. The household's stochastic discount factor (SDF) is:

$$
\mathrm{M}_{t, t+1}=\beta\left(\frac{u_{t+1}}{u_{t}}\right)^{1-\frac{1}{\psi}}\left(\frac{C_{t+1}}{C_{t}}\right)^{-1}\left(\frac{U_{t+1}}{\mathbb{E}_{t}\left[U_{t+1}^{1-\gamma}\right]^{\frac{1}{1-\gamma}}}\right)^{\frac{1}{\psi}-\gamma}
$$


The optimal labor supply is determined by the following condition:

$$
W_{t}^{u}=\frac{\tau C_{t}}{\bar{L}-L_{t}}
$$

As in Uhlig (2007), we assume that only a fraction of the optimal labor supply reaches the market, which results in sticky wages. Formally:

$$
W_{t}=\left(e^{\Delta n_{t}} W_{t-1}\right)^{\mu}\left(W_{t}^{u}\right)^{1-\mu}
$$

where $\mu \in[0,1]$ measures the degree of labor market frictions while $\Delta n_{t}=\ln \left(N_{t} / N_{t-1}\right)$ captures the technology growth rate as will be explained in Equation (25).

Final goods sector. The representative final goods firm produces the output according to:

$$
Y_{t}=\left(K_{t}^{\alpha}\left(A_{t} L_{t}\right)^{1-\alpha}\right)^{1-\xi} \Xi_{t}^{\xi}, \quad \Xi_{t}=\left[\int_{0}^{N_{t}} X_{i, t}^{\nu} d i\right]^{\frac{1}{\nu}},
$$

where $\alpha$ is the capital share, $\xi$ is the share of intermediate goods, and $\nu$ is the elasticity of substitution between intermediate goods in the bundle $\Xi_{t}$. The total number of intermediate goods or patents in the economy is $N_{t}$. Stochastic productivity shocks are induced by the process $A_{t}$ with dynamics:

$$
A_{t}=e^{a_{t}}, \quad a_{t}=\rho_{a} \cdot a_{t-1}+\varepsilon_{a, t},
$$

where $\rho_{a}$ determines the persistence of productivity shocks and $\varepsilon_{a, t} \sim \mathcal{N}\left(0, \sigma_{a}\right)$. The final goods firm maximizes its shareholder value by optimally choosing total capital investment $I_{t}^{*}$, labor $L_{t}$, next period's capital $K_{t+1}$ and the demand for intermediate good $i, X_{i, t}$ :

$$
\max _{\left\{I_{t}^{*}, L_{t}, K_{t+1}, X_{i, t}\right\}_{t \geqslant 0, i \in\left[0, N_{t}\right]}} \mathbb{E}_{0}\left[\sum_{t=0}^{\infty} \mathbb{M}_{0, t} D_{t}\right],
$$

subject to the final good firm's dividends' definition and the capital accumulation equation:

$$
\begin{aligned}
D_{t} & =Y_{t}-I_{t}-W_{t} L_{t}-\int_{0}^{N_{t}} P_{i, t} X_{i, t} d i, \\
K_{t+1} & =(1-\delta) K_{t}+\Lambda\left(\frac{I_{t}^{*}}{K_{t}}\right) K_{t}, \\
I_{t} & =\left(1-\tau_{i n v, t}\right) I_{t}^{*}
\end{aligned}
$$


where $P_{i, t}$ is the price of intermediate good $i, \delta$ is the capital depreciation rate, and $\Lambda\left(I_{t}^{*} / K_{t}\right)=$ $\frac{\alpha_{1}}{1-1 / \zeta}\left(I_{t}^{*} / K_{t}\right)^{1-1 / \zeta}+\alpha_{2}$ is the adjustment cost function transforming investment in new capital as in Jermann (1998). The constants $\alpha_{1}$ and $\alpha_{2}$ are calibrated such that adjustment costs are zero in the deterministic steady state.

Moreover, the government subsidizes capital investment by transferring a fraction $\tau_{i}$ of its total government expenditure to the final goods firm. This implies that only a fraction of total capital investment $I_{t}^{*}$ has to be supplied by the final goods firm, i.e., $I_{t}=\left(1-\tau_{i n v, t}\right) I_{t}^{*}$. The remaining fraction $\tau_{i n v, t}$ is paid as a subsidy by the government. In particular, it holds that $\tau_{i} G_{t}=\tau_{i n v, t} I_{t}$. The resulting equilibrium conditions are as follows:

$$
\begin{aligned}
\frac{1-\tau_{i n v, t}}{\Lambda^{\prime}\left(\frac{I_{t}^{*}}{K_{t}}\right)} & =\mathbb{E}_{t}\left[\mathbb{M}_{t, t+1}\left\{\frac{(1-\xi) \alpha Y_{t+1}-\left(1-\tau_{i n v, t+1}\right) I_{t+1}^{*}}{K_{t+1}}+\frac{\left(1-\tau_{i n v, t+1}\right)\left(\Lambda\left(\frac{I_{t+1}^{*}}{K_{t+1}}\right)+1-\delta\right)}{\Lambda^{\prime}\left(\frac{I_{t+1}^{*}}{K_{t+1}}\right)}\right\}\right] \\
W_{t} & =\frac{(1-\xi)(1-\alpha) Y_{t}}{L_{t}} \\
X_{i, t}\left(P_{i, t}\right) & =\left(\frac{\xi Y_{t}}{P_{i, t}}\right)^{\frac{1}{1-\nu}} \Xi_{t}^{\frac{\nu}{\nu-1}}
\end{aligned}
$$

Intermediate goods sector. Each intermediate good $i \in\left[0, N_{t}\right]$ is produced by an atomistic, monopolistically competitive firm facing the maximization problem:

$$
\max _{\left\{P_{i, t}\right\}}\left\{\Pi_{i, t}\right\}=\max _{\left\{P_{i, t}\right\}}\left\{P_{i, t} X_{i, t}\left(P_{i, t}\right)-X_{i, t}\left(P_{i, t}\right)\right\}
$$

A symmetric equilibirum is obtained by solving the maximization problem (17):

$$
\begin{aligned}
P_{i, t} & \equiv P_{t}=\frac{1}{\nu} \\
\Pi_{i, t} & \equiv \Pi_{t}=\left(\frac{1}{\nu}-1\right) X_{t}, \\
X_{i, t} & \equiv X_{t}=\left(\xi \nu\left(K_{t}^{\alpha}\left(A_{t} L_{t}\right)^{1-\alpha}\right)^{1-\xi} N_{t}^{\frac{\xi}{\nu}-1}\right)^{\frac{1}{1-\xi}} .
\end{aligned}
$$

Substituting Equation (20) into the production function (8) and imposing the following restriction to ensure balanced growth, i.e., $1-\alpha=(\xi / \nu-\xi) /(1-\xi)$, implies:

$$
Y_{t}=(\xi \nu)^{\frac{\xi}{1-\xi}} K_{t}^{\alpha}\left(A_{t} N_{t} L_{t}\right)^{1-\alpha}
$$


Finally, the value $V_{i, t} \equiv V_{t}$ of owning exclusive rights to produce intermediate good $i$ using the respective patent $i$ is equal to the present value of the current and future monopoly profits:

$$
V_{i, t} \equiv V_{t}=\left(1-\tau_{\pi}\right) \Pi_{t}+\kappa_{t} \mathbb{E}_{t}\left[\mathrm{M}_{t, t+1} V_{t+1}\right]
$$

where $\tau_{\pi}$ is the constant tax rate levied by the government on the profits of intermediate goods firms and $\kappa_{t}=e^{\theta_{t}}(1-\phi)$. We assume that the depreciation of patents is stochastic, i.e., ${ }^{8}$

$$
\theta_{t}=\rho_{\theta} \theta_{t-1}+\tau_{T} \varepsilon_{T, t} .
$$

In the absence of depreciation shocks, $\phi$ is the probability that a patent becomes obsolete. The parameter $\tau_{T}$ measures the sensitivity of the obsolescence rate to temperature shocks and $\rho_{\theta}$ measures the persistence of these depreciation shocks. ${ }^{9}$ We capture global warming effects by assuming that unexpected changes in the obsolescence rate are induced by temperature shocks. As a potential channel how temperature shocks affect the accumulation of patents, one can think of non-green ("dirty") technologies becoming obsolete due to climate change, which reduces the productivity in the economy, for example. We calibrate the sensitivity parameter $\tau_{T}$ such that the model matches the magnitude of the negative effects of temperature shocks on R\&D expenditure growth, observed in the data.

Temperature dynamics. As in Bansal and Ochoa (2011b), global temperature $T_{t}$ evolves according to:

$$
T_{t}=\mu_{T}+\rho_{T}\left(T_{t-1}-\mu_{T}\right)+\varepsilon_{T, t},
$$

where $\rho_{T}$ is the persistence parameter, $\mu_{T}$ is the long-run mean of global temperature, and $\varepsilon_{T, t} \sim \mathcal{N}\left(0, \sigma_{T}\right)$.

Innovation sector. The number of intermediate goods $N_{t}$ evolves according to:

$$
N_{t+1}=\vartheta_{t} S_{t}+\kappa_{t} N_{t}
$$

\footnotetext{
${ }^{8}$ In this respect, we are close to Furlanetto and Seneca (2014) who introduce a stochastic depreciation rate into a standard New Keynesian model.

${ }^{9}$ For parsimony, we only focus on temperature shocks as a source of depreciation risk and do not introduce the shock component, $\sigma_{\theta} \epsilon_{\theta}$. Simulations including the latter confirm that this additional source of risk would not affect our quantitative results.
} 
where $S_{t}$ denotes the economy's expenditure in research and development $(\mathrm{R} \& \mathrm{D})$. The innovation sector's productivity $\vartheta_{t}$ that is taken as given by innovating firms has the functional form:

$$
\vartheta_{t}=\chi\left(\frac{S_{t}}{N_{t}}\right)^{\eta-1}
$$

where $\chi$ is a $R \& D$ productivity shift parameter, and $\eta$ determines the elasticity of $R \& D$ investment. ${ }^{10}$

The payoff to innovation is the expected value of discounted future profits on a patent (i.e., $\left.\mathbb{E}_{t}\left[\mathrm{M}_{t, t+1} V_{t+1}\right]\right)$. Thus, free entry into the innovation sector implies:

$$
\mathbb{E}_{t}\left[\mathrm{M}_{t, t+1} V_{t+1}\right]\left(N_{t+1}-\kappa_{t} N_{t}\right)=S_{t},
$$

which states that the expected sales revenues equal the innovation costs.

Government and fiscal policy. The ratio of government expenditure to output $G_{t} / Y_{t}$ is exogenously determined by the following stochastic process which ensures that $G_{t} / Y_{t} \in(0,1)$ :

$$
\begin{aligned}
\frac{G_{t}}{Y_{t}} & =\frac{e^{g y_{t}}}{1+e^{g y_{t}}}, \\
g y_{t} & =\left(1-\rho_{g y}\right) \overline{g y}+\rho_{g} g y_{t-1}+\varepsilon_{g y, t},
\end{aligned}
$$

where $\varepsilon_{g y, t} \sim \mathcal{N}\left(0, \sigma_{g}\right), \rho_{g y}$ determines the persistence of shocks to the government expenditure to output ratio, and $\overline{g y}$ is the long-run mean of the government expenditure to output ratio. We assume for simplicity that the government has to comply with a zero-deficit condition and is not allowed to run any fiscal deficits. Therefore, it has to finance its expenditure level each period by taxes. Government spending consists of fiscal transfers and the potential remaining part $Z_{t}$ which is considered as wasteful, i.e., $Z_{t}=\left(1-\tau_{i}\right) G_{t}$. Assuming $\tau_{i} \leqslant 1$ assures that government subsidies are never larger than the total government expenditure. This implies that the government budget constraint is:

$$
G_{t}=\tau_{l, t} W_{t} L_{t}+\tau_{\pi} N_{t} \Pi_{t}=\tau_{i} G_{t}+Z_{t}
$$

\footnotetext{
${ }^{10}$ An alternative way of modeling temperature effects in this setup is to let temperature shocks affect the $R \& D$ productivity shift parameter $\chi$ instead of the obsolescence rate of patents $\phi$. Simulations show that both specifications produce similar impulse responses.
} 
Furthermore, this implies that the labor tax rate is determined by:

$$
\tau_{l, t}=\frac{G_{t}-\tau_{\pi} N_{t} \Pi_{t}}{W_{t} L_{t}}
$$

Aggregate resource constraint. Final goods output is used for consumption, purchasing intermediate goods, capital investment, R\&D expenditure, and government spending. Hence, the aggregate resource constraint reads:

$$
Y_{t}=C_{t}+N_{t} X_{t}+I_{t}+S_{t}+G_{t}=C_{t}+N_{t} X_{t}+I_{t}^{*}+S_{t}+Z_{t}
$$

Aggregate dividends are given by the sum of corporate profits of the final goods firm and the continuum of intermediate goods producers:

$$
D_{a, t}=C_{t}+S_{t}-\left(1-\tau_{l, t}\right) W_{t}^{u} L_{t}=Y_{t}-N_{t} X_{t}-I_{t}-G_{t}-\left(1-\tau_{l, t}\right) W_{t}^{u} L_{t}=D_{t}+\left(1-\tau_{\pi}\right) N_{t} \Pi_{t} .
$$

Asset prices. We study the dynamics of two asset prices in this economy: a risk-free bond and the aggregate market's stock price. First, the risk-free rate solves:

$$
r_{f, t}=\ln \left(R_{f, t}\right), \quad R_{f, t}=\frac{1}{\mathbb{E}_{t}\left[\mathrm{M}_{t, t+1}\right]}
$$

Second, the aggregate market's stock price, its return, and its risk premium are given by:

$$
\begin{aligned}
V_{a, t} & =D_{a, t}+\mathbb{E}_{t}\left[\mathrm{M}_{t, t+1} V_{a, t+1}\right], \\
R_{a, t} & =\frac{V_{a, t}}{V_{a, t-1}-D_{a, t-1}}, \\
r_{a, t}-r_{f, t} & =(1+\varphi)\left(\ln \left(R_{a, t}\right)-r_{f, t}\right),
\end{aligned}
$$

where the final good sector excess return is levered by imposing $\varphi=1$ (see Croce, 2014; Gao, Hitzemann, Shaliastovich, and Xu, 2016).

\section{Calibration}

Parameter values for the benchmark economy are reported in Table II. To be consistent with our bi-variate VAR analysis in Section 3, we calibrate the model to (cross-country average) G7 
data and to an annual frequency. We set the standard parameters in line with the literature on long-run risk. As in Kung and Schmid (2015) we set $\beta=0.984, \psi=1.85, \gamma=10, \alpha=0.35$, and $\delta=0.08$. We then impose $\eta=0.8$ in order to obtain a volatility of R\&D investments close to the data. To achieve that investment is more volatile than output as in the data, we set the adjustment cost parameter, $\zeta$, to a value of 0.8 . The inverse of the monopoly markup parameter is equal to $1 / 1.5$ which is close to the value used by Kung and Schmid (2015). The long-run mean $R \& D$ depreciation rate, $\phi$, is set to 0.09 as in Bena, Garlappi, and Grüning (2016). The wage rigidity parameter $\mu$ is set to 0.35 as in Uhlig (2007).

\section{Table II: Model Parameter VAlues}

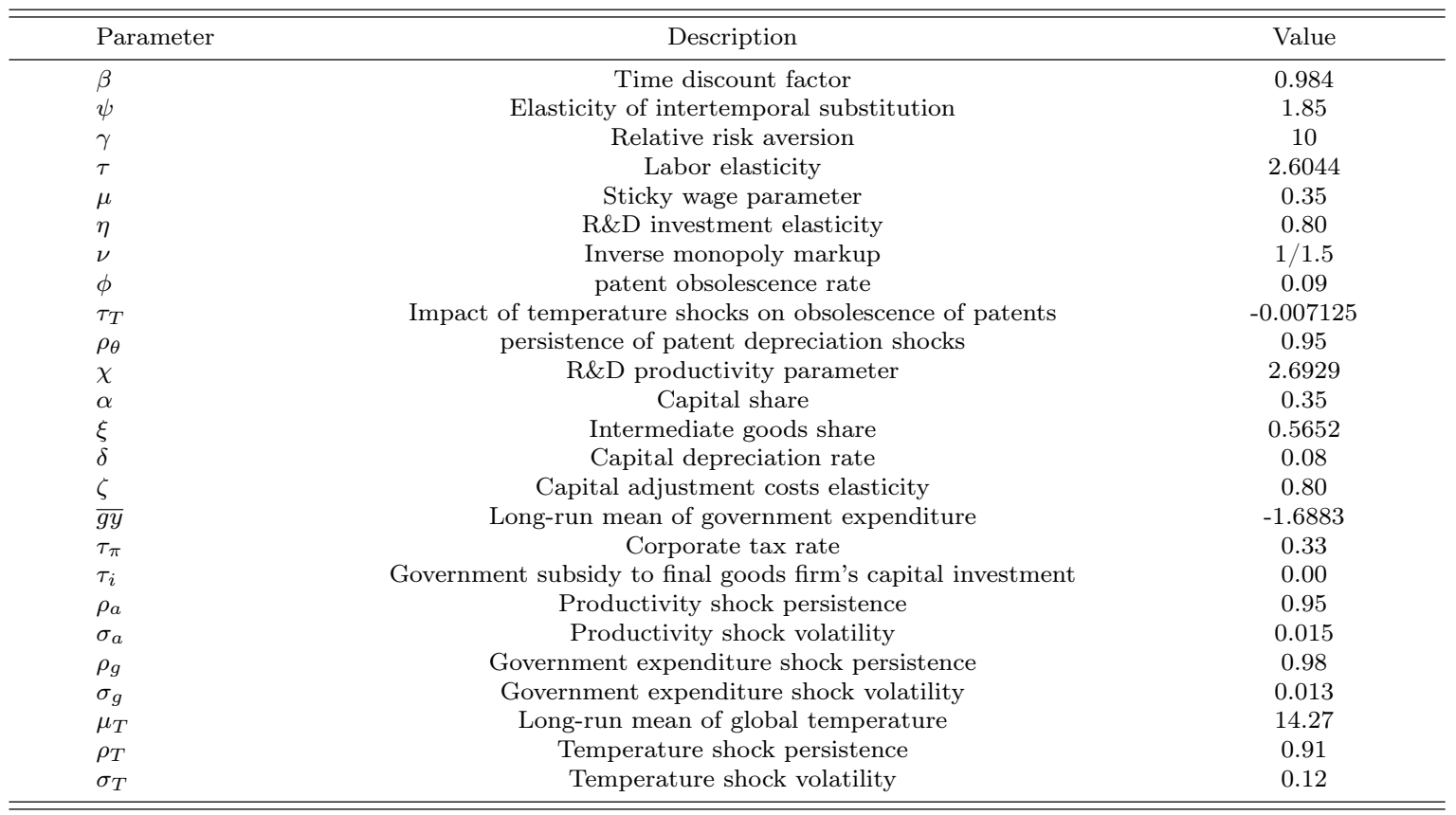

Notes: This table reports the parameters we use in the annual calibration of the model described in Section 4 .

The cross-country (G7) average corporate tax rate, $\tau_{\pi}$, is set to 0.33 , as suggested by KPMG for the period 2011-2017. In our benchmark calibration, we assume that fiscal policy does not subsidize investments of final goods firms. Therefore, we set $\tau_{i}$ equal to 0 . Loosely speaking, this represents an economy in which policymakers do not care about climate risk. To match the Penn World Table (PWT) data on government spending for the G7 countries, we set the parameters $\rho_{g}, \overline{g y}$, and $\sigma_{g}$ to values of $0.98,-1.6883$, and 0.013 , respectively. These numbers are also in line with the calibration of Donadelli and Grüning (2017).

The persistence of TFP shocks, $\rho_{a}$, with a value of 0.95 is as in Kung and Schmid (2015). The volatility of productivity shocks $\sigma_{a}$ is set to 0.015 to match the observed volatility of output in the data. 
The persistence of depreciation shocks is chosen to let the model reproduce the persistent effect of temperature shocks on $R \& D$ growth observed in the data. To this end, we set $\rho_{\theta}=0.95$. The parameter $\tau_{T}$, measuring the impact of temperature shocks on R\&D growth, is calibrated to a value of -0.007125 , which implies in our model that $R \& D$ growth declines by around $0.6 \mathrm{pp}$ after an unexpected one standard deviation increase in temperature.

The other parameters regarding temperature dynamics are set to match the global temperature statistics observed in the data over the period 1975-2015. In particular, we set $\mu_{T}=14.27$ (degrees Celsius), $\sigma_{T}=0.12$, and $\rho_{T}=0.91$ to match the long-term mean and volatility of global temperature. ${ }^{11}$

We then solve the model numerically by a third-order approximation using perturbation methods, as provided by the dynare++ package.

\section{Quantitative Implications}

Simulated moments. The main results produced by our benchmark calibration are reported in Table III, specification [1]. Compared to the economy with no temperature effects (specification [2]), we observe that the impact of temperature on the obsolescence rate of patents is responsible for a 17 basis points (bps) increase in both the average equity premium and its volatility. Since the agent has a preference for early resolution of uncertainty, the negative effect of temperature shocks on the economy is priced. The adverse economic effects of temperature shocks are reflected by a negative correlation between $R \& D$ expenditures and global temperature at -0.10 , consistent with empirical evidence.

Inspecting the mechanism. Impulse responses of macro aggregates to a one standard deviation increase in global temperature are displayed in Figure 2. Unexpected temperature increases are transmitted to the business cycle via their negative effect on the accumulation of patents. The latter drives the endogenous technical progress and growth in our model. More precisely, positive temperature shocks increase the depreciation of patents today and in the future. Consequently, the adverse and long-lasting effect on the accumulation of patents translates into

\footnotetext{
${ }^{11}$ Note that the value of the persistence parameter $\rho_{T}$ is as in Bansal and Ochoa (2011b). Moreover, it is in line with the autocorrelation structure of global temperature observed in the data.
} 
Table III: Model vs Data: Macroeconomic Quantities and Asset Prices

\begin{tabular}{lccc}
\hline \hline Variable & Data & Benchmark & $\tau_{T}=0$ \\
\hline MACRO QUANTITIES & & {$[\mathbf{1}]$} & {$[\mathbf{2}]$} \\
\hline $\mathbb{E}(\Delta c)$ & 2.25 & $\mathbf{2 . 2 1}$ & 2.21 \\
$\sigma(\Delta y)$ & 1.60 & $\mathbf{1 . 6 0}$ & 1.60 \\
$\sigma(\Delta c)$ & 1.20 & $\mathbf{1 . 0 1}$ & 0.93 \\
\hline$\sigma(\Delta c) / \sigma(\Delta y)$ & 0.75 & $\mathbf{0 . 6 2}$ & 0.58 \\
$\sigma\left(\Delta i^{*}\right) / \sigma(\Delta y)$ & 2.05 & $\mathbf{1 . 0 3}$ & 1.02 \\
$\sigma(\Delta s) / \sigma(\Delta y)$ & 1.92 & $\mathbf{2 . 1 4}$ & 0.14 \\
\hline$(\Delta c, \Delta y)$ & 0.87 & $\mathbf{0 . 3 7}$ & 0.33 \\
$\rho\left(\Delta c, \Delta i^{*}\right)$ & 0.81 & $\mathbf{0 . 2 6}$ & 0.99 \\
$\rho\left(\Delta i^{*}, \Delta y\right)$ & 0.93 & $\mathbf{0 . 9 9}$ & 0.97 \\
$\rho(\Delta s, \Delta y)$ & 0.59 & $\mathbf{0 . 9 7}$ & 0.00 \\
$\rho(\Delta s, T)$ & -0.46 & $\mathbf{- 0 . 1 0}$ & 14.27 \\
\hline TEMPERATURE & & & 0.23 \\
\hline $\mathbb{E}(T)$ & 14.27 & $\mathbf{1 4 . 2 7}$ & \\
$\sigma(T)$ & 0.23 & $\mathbf{0 . 2 3}$ & 2.34 \\
\hline ASSET PRICES & & & 0.22 \\
\hline $\mathbb{E}\left(r_{f}\right)$ & 2.31 & $\mathbf{2 . 3 1}$ & 1.51 \\
$\sigma\left(r_{f}\right)$ & 2.88 & $\mathbf{0 . 2 5}$ & 4.69 \\
$\mathbb{E}\left[r_{a}-r_{f}\right]$ & 5.72 & $\mathbf{1 . 6 8}$ & $\mathbf{4 . 8 3}$ \\
$\sigma\left(r_{a}-r_{f}\right)$ & 14.72 & & \\
\hline \hline
\end{tabular}

Notes: This table reports the main moments for the benchmark calibration (specification [1]) and the model where temperature does not affect the obsolescence rate of patents (specification [2]), i.e., $\tau_{T}=0$ in Equation (23). The aggregate market return is levered as in Croce (2014). Models' entries are obtained from repetitions of small-sample simulations (i.e., averages over 1000 simulations of 41 years). $\mathbb{E}[\cdot], \sigma(\cdot)$ and $\rho(\cdot, \cdot)$ denote mean, volatility, and correlation, respectively. Means and standard deviations are expressed in percentage points. Data on Global temperature and G7 macro-aggregates are from the Climate Research Unit and the OECD, respectively. Data are annual and run from 1975 (or later) to 2015. Additional details on the data are provided in Appendix A.

a persistent decline in TFP growth. This implies that temperature shocks constitute a source of endogenous long-run productivity risk.

It is worth noting that the decrease in productivity triggers both a substitution and an income effect on macro variables. On the one hand, lower productivity decreases the opportunity costs of consumption such that the agents want to immediately reduce labor and investments in both $\mathrm{R} \& \mathrm{D}$ and capital in order to increase consumption today. On the other hand, the decline in productivity decreases the income of agents, which results into long-lasting losses in output, investments in both $\mathrm{R} \& \mathrm{D}$ and capital, and consumption. Moreover, future labor supply has to be increased in order to compensate for lower productivity. Finally, the persistent adverse effects on the accumulation of patents also harms the accumulation of capital. The response for physical capital is positive on impact since the immediate fall of investment reduces capital one period later according to the capital accumulation process. 
Panel A: $T \rightarrow \Delta S$

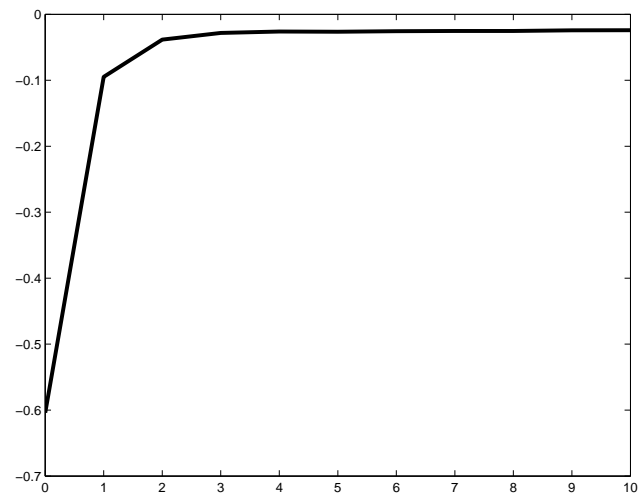

PANEL C: $T \rightarrow \Delta Y$

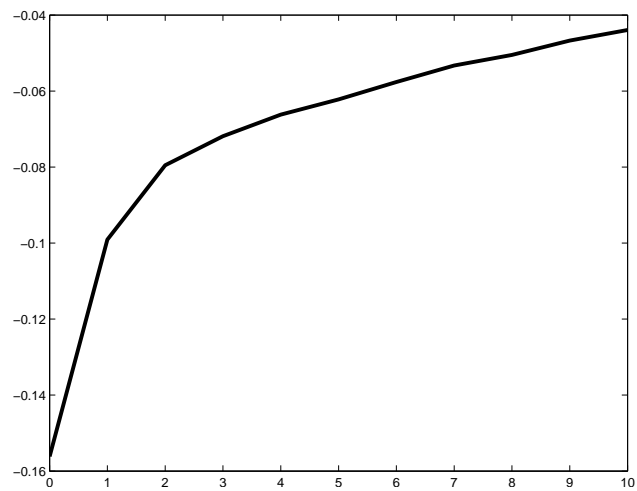

PANEL E: $T \rightarrow \Delta L$

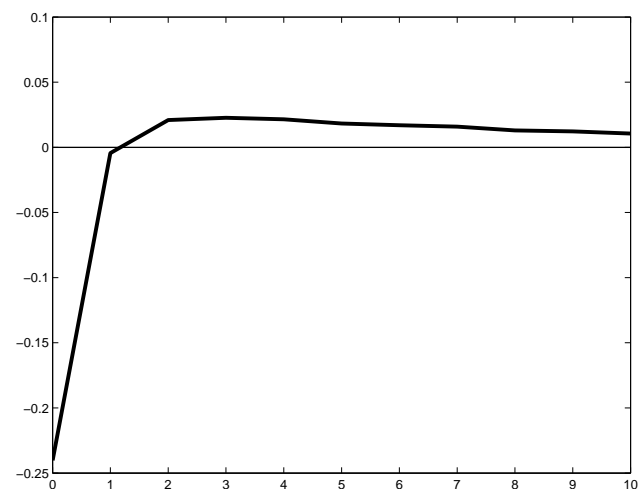

PANEL B: $T \rightarrow \Delta C$

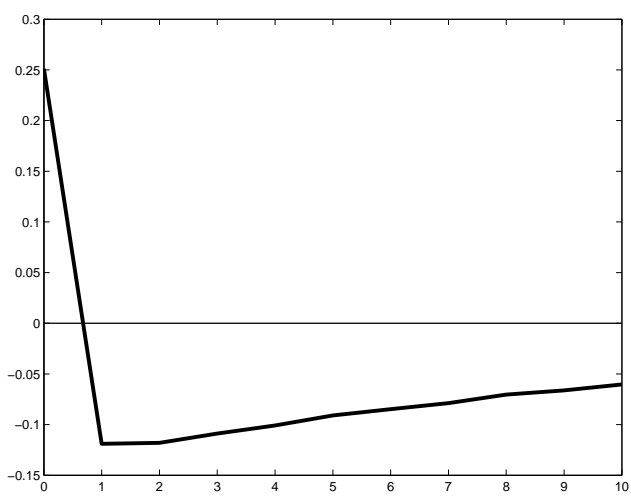

PANEL D: $T \rightarrow \Delta I^{*}$

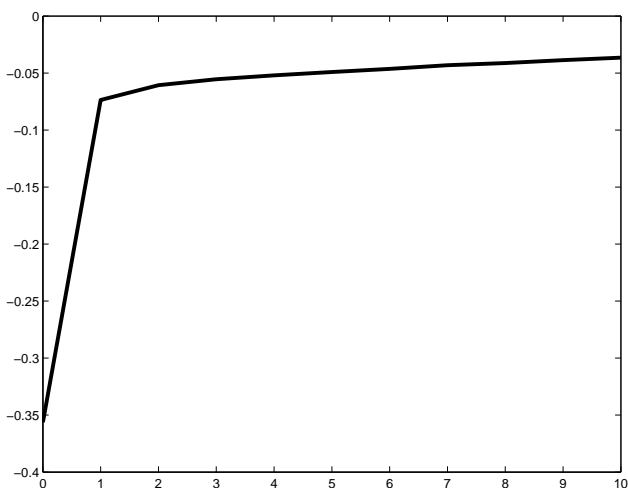

PANEL F: $T \rightarrow \Delta K$

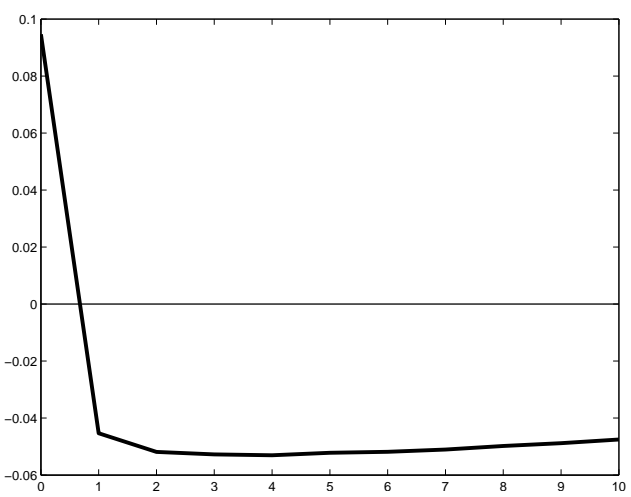

Notes: This figure reports impulse responses (expressed as deviation from the steady state in percentage points) for a length of 10 years of R\&D growth, $\Delta S$, consumption growth, $\Delta C$, output growth, $\Delta Y$, investment growth, $\Delta I^{*}$, labor growth, $\Delta L$, and capital growth, $\Delta K$, with respect to a temperature shock $\left(\varepsilon_{T}>0\right)$. All the parameters are calibrated to the values reported in Table II, specification 1 .

Expected growth losses. To quantify the long-term effects of temperature increases, we calculate expected losses in GDP productivity growth for horizons from 1 to 50 years ahead after a temporary positive shock to global temperature. To this end, we compare the cumulative growth in an economy in which temperature negatively affects the obsolescence rate of patents to cumulative growth to an economy without temperature risk. The shock sizes are one and two 
standard deviations of temperature changes, i.e., $0.12^{\circ} \mathrm{C}$ and $0.24^{\circ} \mathrm{C}$, respectively.

Results for expected output growth losses are reported in Table IV. After half a century, a single initial temperature shock decreases cumulative GDP growth by $1.42 \mathrm{pp}$. If the size of the temperature shock is twice as high, growth losses are doubled as well and amount to 2.84pp. The estimates in Table IV may appear to be small, but one should keep in mind that our exercise is based on a single temperature shock only and does not take into account a possible accumulation of several positive temperature increases over the next century.

\section{Table IV: Long-Run Effects of Temperature Shocks}

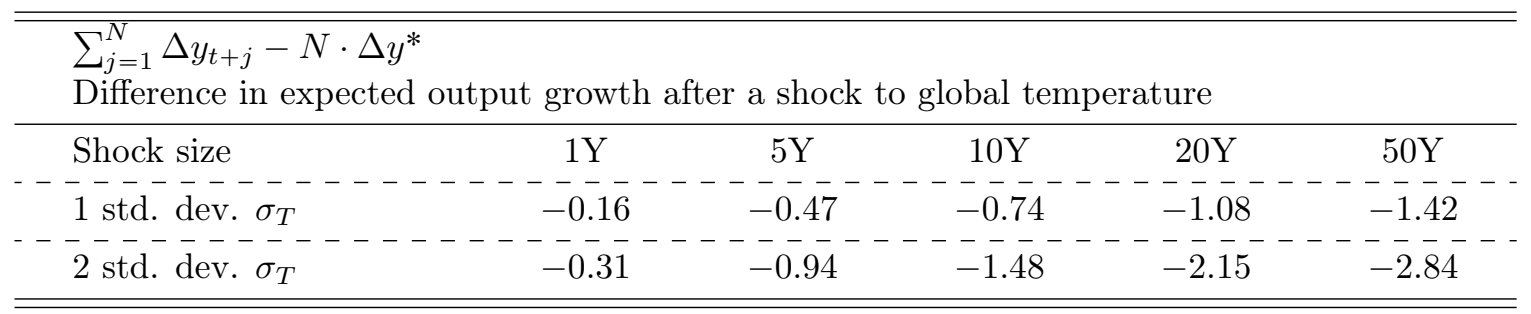

Notes: This table reports the cumulative change in output growth over $1,5,10,20$, and 50 years in percentage points after a temporary temperature shock. The cumulative growth in an economy without such a shock is compared to that in an economy with shocks to temperature, $z_{t}$. Specifically, we report $\left(\sum_{j=1}^{N} \Delta y_{t+j}\right)-N \cdot \Delta y^{*}$ where $\Delta y_{t+j}$ is the $\log$ growth rate of total output, and $\Delta y^{*}$ is the steady state growth rate in the economy without a shock (i.e., with $\varepsilon_{T}=0$ ). For example, the entry -0.46 for a horizon of 5 years in the first row means that cumulative output growth over these 5 years has been 0.46 percentage points lower than it would have been without the temperature shock. The amount of lost output growth is reported for temperature shocks amounting to one and two standard deviations, i.e., to $0.12^{\circ} \mathrm{C}$ and $0.24^{\circ} \mathrm{C}$, respectively.

Welfare costs. Following Croce, Kung, Nguyen, and Schmid (2012), welfare costs are defined as the percentage increase of time-zero utility bundle units $\Delta$ that one must give to the household in order to make it indifferent between the utility bundle process of the benchmark calibration $\{u\}$ and the utility bundle process of the economy without temperature effects $\left\{u^{*}\right\}$ :

$$
e^{\hat{U}}=(1+\Delta) e^{\hat{U}^{*}},
$$

where $\hat{U}$ denotes the natural logarithm of the ratio of the utility $U$ to the initial number of intermediate goods $N$.

Table V displays welfare costs for temperature effects in the benchmark economy. In our benchmark calibration, welfare costs amount to $11.09 \%$. According to our specification of the utility bundle, this implies that the time-zero utility consumption units of an agent living in an economy with temperature risk needs to be increased by about $11 \%$ to give the agent the same utility as in an economy without temperature risk. 
Table V: Welfare Costs of Temperature Risk

\begin{tabular}{ccc}
\hline \hline & {$\left[\tau_{T}=0\right]$} & {$\left[\tau_{T}=-0.007125\right]$} \\
\hline $\mathbb{E}(\hat{U})$ & 0.9756 & 0.8782 \\
$\Delta$ & - & $11.09 \%$ \\
\hline \hline
\end{tabular}

Notes: This table reports the welfare costs of temperature shocks. Welfare costs are defined as the percentage increase $\Delta>0$ in time-zero utility bundle units that the household should receive in order to be indifferent between living in an economy with full risk exposure (i.e., $\sigma_{T}, \sigma_{a}, \sigma_{g}>0$ ) and an economy without temperature effects. Temperature effects are eliminated by imposing $\tau_{T}=0$.

Investment subsidies. Given that temperature shocks produces sizable welfare costs, the question that one may think of is how the government should respond to temperature risk in order to offset these costs. One possibility for the government is to subsidize capital investments of final goods firms in order to promote higher economic growth. Note that one can interpret this as a form of adaption. As found in Section 3, a positive temperature shock reduces growth in R\&D expenditure. Our model further suggests that this adverse effect also translates into lower growth of capital investments and output. Higher investment subsidies make investments more profitable by increasing opportunity costs of consumption, such that households postpone consumption now to invest in order to stimulate consumption later. Hence, higher capital investment subsidies lead to higher capital investment and higher R\&D investments compared to the benchmark. This way, the government can offset the negative effects of temperature shocks on R\&D and increase overall welfare of households.

Figure 3: Welfare Costs of Global Temperature Risk vs. $\tau_{i}$

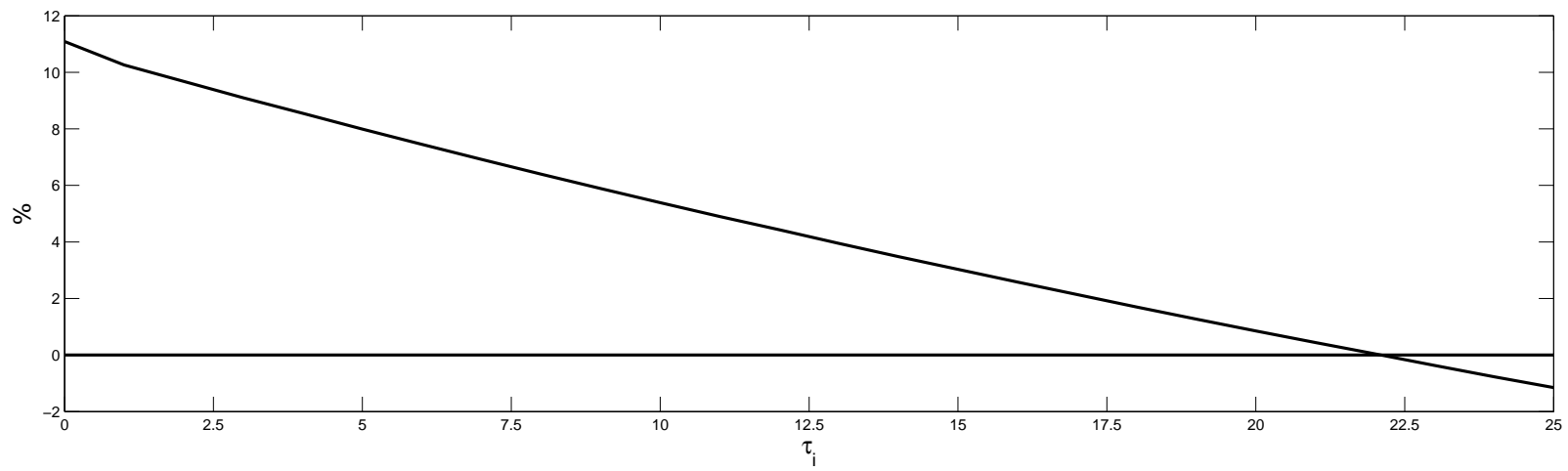

Notes: This figure reports welfare costs for different values of the capital investment subsidy rate, $\tau_{i}$. Welfare costs are computed as in Equation (38). All the remaining parameters are set to the values reported in Table II.

In this respect, we calculate the required rate of investment subsidies such that welfare costs of temperature risk are zero. The welfare costs are then calculated by comparing the welfare 
in the economy without temperature risk and without investment subsidies to the welfare in the economy with temperature risk and a positive subsidy rate on investment. Figure 3 depicts welfare costs of temperature risk as a function of the subsidy rate $\tau_{i}$. As higher investment subsidies promote economic growth, welfare costs of temperature risk are found to be a decreasing function of $\tau_{i}$. We find that the government should subsidize capital investments with a rate of $22.2 \%$ of total government expenditures to offset welfare costs of temperature risk. Simulated moments for the economy with $\tau_{i}=0.222$ are reported in Table C.I in Appendix C. Welfare gains produced by investment subsidies are followed by a small increase in consumption growth $(+7 \mathrm{pp})$. Due to the stimulation of investments into capital, the investment to output ratio $\left(I^{*} / Y\right)$ increases from $14.2 \%$ to $17.7 \%$ in the steady state. Moreover, we observe an increase in the equity premium of $17 \mathrm{bps}$.

\section{Further Inspection of the Mechanism}

In this section, we perturb our benchmark model in order to study whether the effects of a global temperature shock on R\&D dynamics change in the presence of (i) a different tax regime, (ii) an economy where final output depends less on patents, and (iii) a different assumption regarding how temperature shocks affect the depreciation rate of patents. For the sake of brevity, results from these analyses are reported in Appendix C. The main economic intuitions are addressed in what follows.

Different tax regime. Previously, we have assumed that the government is committed to comply with a zero-deficit rule. To assess the robustness of our results to different tax regimes, we now allow the government to run fiscal deficits, as described by the equations in Appendix C.2. By issuing debt, the government may stabilize economic fluctuations as it is able to employ tax smoothing policies. During recessions, it can increase government debt to allow for lower labor taxes while debt can be reduced during economic expansions by raising taxes. It is therefore straightforward to test whether these government policies are able to reduce the impact of temperature fluctuations on the business cycle and welfare. Simulated moments, welfare costs, and expected growth losses for the new tax regime are reported in Tables C.II, C.III, and C.IV, respectively. Results under the new tax regime are basically identical to the case where the government was restricted by a zero-deficit rule. Hence, the quantitative implications from our 
model do not depend on the assumptions about the tax regime employed by the government. ${ }^{12}$

Decreasing role of R\&D. In our framework, we assume that temperature shocks affect the accumulation of patents with the latter being the main driver of economic growth. This raises the question of how sensitive our results are to the importance of $R \& D$ in the economy. Strictly speaking, does temperature risk still matter if the role of $R \& D$ for economic growth decreases? We test for this by lowering the share of intermediate goods (patents), $\xi$, in the production function of final goods firms from our benchmark value of 0.5652 to a value of 0.3 . Due to the balanced growth path restriction, we also need to increase the monopoly markup parameter to $\nu=1 / 2.5167$ in this case. The lower $\xi$, the smaller is the contribution of $\mathrm{R} \& \mathrm{D}$ to economic growth in the model, since the accumulation of patents becomes relatively less important compared to labor and the accumulation of capital.

In Appendix C.3, we report simulated moments (Table C.V), welfare costs of temperature risk (Table C.VI), expected growth losses (Table C.VII), and welfare costs of temperature risk as a function of the investment subsidy rate (Figure C.1). Our main results are left unchanged. Temperature risk still produces an equity risk premium of 16bps and generates substantial welfare costs of about 10\%. Expected growth losses are also reduced but only to a very small extent. The main difference is that the required investment subsidy rate to offset welfare costs by temperature risk is higher compared to the benchmark economy and amounts to $27.9 \%$. As described above, a higher capital investment subsidy rate leads to both an increase in capital investment and R\&D investments. However, due to the smaller share of intermediate goods (patents) in the production of aggregate output, the welfare benefits of increasing $R \& D$ investments are lower compared to the benchmark. Therefore, a larger subsidy rate on capital investment is required to offset welfare costs of temperature risk.

Different temperature risk. In the benchmark model, unexpected temperature shocks induce a decrease in $\mathrm{R} \& \mathrm{D}$ expenditures and thus lower economic growth due to their impact on the depreciation rate of patents. In this section, we analyze a model specification, for which all the details and results are reported in Appendix C.4, in order to investigate if the model is robust with respect to the concrete way how temperature risk affects the macro economy. To

\footnotetext{
${ }^{12}$ Besides the employment-oriented tax rule according to Equation (C.3), we also tested other rules focusing on deviations of output, consumption, or firm profits. Implications for welfare and business cycles remain unchanged.
} 
this extent, we specify the process $\theta_{t}$ as follows:

$$
\theta_{t}=\tau_{T}\left(T_{t}-\mu_{T}\right) .
$$

With this specification, it is not unexpected temperature shocks that affects the patent depreciation rate but instead temperature deviations from the long-run mean. Due to the lower persistence in temperature compared to the persistence of patent depreciation shocks in Equation (23), the quantitative effects are smaller. Hence, welfare costs of temperature risk amount to only $6.89 \%$ of lifetime consumption, the capital investment subsidy rate needed to compensate for this welfare loss is just equal to $14.5 \%$ of government expenditures, and one has to set $\tau_{T}=-0.00901$ instead of $\tau_{T}=-0.007125$ in the benchmark model in order to obtain a $0.6 \mathrm{pp}$ decrease in $\mathrm{R} \& \mathrm{D}$ expenditure growth in response to a temperature shock. However, this way of modeling temperature risk qualitatively provides very similar results. Hence, our main results are robust with respect to the way that temperature risk affects the macro economy.

\section{Concluding Remarks}

We provide novel empirical evidence suggesting that a global temperature shock has adverse effects on aggregate expenditure in $\mathrm{R} \& \mathrm{D}$. We account for this evidence by augmenting a stochastic endogenous growth model with global temperature risk. As in the data, temperature risk undermines both innovation and investment in physical capital. This results in sizable welfare costs that amount to $11.1 \%$ of lifetime utility. Such costs can be offset by subsidizing aggregate capital investment with $22.2 \%$ of total government spending.

This paper is a first attempt to account for climate change-related phenomena in a stochastic endogenous growth setting. Of course, it can be fruitfully extended under several dimensions. First, it is net of many forms of adaptation such as factor reallocation, transfers, defensive investments, and price changes. Second, it focuses only on temperature as climate change-related shocks. However, there is evidence suggesting that other climate-change related phenomena affect economic activity (e.g., precipitation, hurricanes' frequency, etc.). Third, growth is sustained by homogeneous innovations by entrants only. Coupling temperature risk and heterogeneous innovations could also be worth developing. We leave these model extensions for future research. 


\section{References}

Angelopoulos, K., G. Economides, And A. Philippopoulos (2013): "First-and secondbest allocations under economic and environmental uncertainty," International Tax and Public Finance, 20(3), 360-380.

Annicchiarico, B., And F. Di Dio (2015): "Environmental policy and macroeconomic dynamics in a new Keynesian model," Journal of Environmental Economics and Management, $69,1-21$

(2017): "GHG emissions control and monetary policy," Environmental and Resource Economics, 67(4), 823-851.

BAnsal, R., AND M. OChOA (2011a): "Temperature, aggregate risk, and expected returns," NBER Working Paper No. 17575.

(2011b): "Welfare costs of long-run temperature shifts," NBER Working Paper No. 17574

Bena, J., L. Garlappi, And P. GrÜning (2016): "Heterogeneous Innovation, Firm Creation and Destruction, and Asset Prices," The Review of Asset Pricing Studies, 6(1), 46-87.

Colacito, R., B. Hoffmann, And T. Phan (2016): "Temperature and growth: A panel analysis of the United States," Working Paper.

Croce, M., T. Nguyen, And L. Schmid (2013): "Fiscal Policy and the Distribution of Consumption Risk," Working Paper.

— (2014): "Global Entropy," Working Paper.

Croce, M. M. (2014): "Long-run productivity risk: A new hope for production-based asset pricing?," Journal of Monetary Economics, 66, 13-31.

Croce, M. M., H. Kung, T. T. Nguyen, And L. Schmid (2012): "Fiscal Policies and Asset Prices," The Review of Financial Studies, 25(9), 26-35.

Dell, M., B. F. Jones, And B. A. Olken (2012): "Temperature shocks and economic growth: Evidence from the last half century," American Economic Journal: Macroeconomics, $4(3), 66-95$. 
Deryugina, T., And S. M. Hsiang (2014): "Does the environment still matter? Daily temperature and income in the United States," NBER Working Paper No. 20750.

Dietz, S., And N. STERn (2015): "Endogenous growth, convexity of damage and climate risk: How Nordhaus' framework supports deep cuts in carbon emissions," The Economic Journal, $125(583), 574-620$.

Donadelli, M., AND P. Grüning (2017): "Innovation Dynamics and Fiscal Policy: Implications for Growth, Asset Prices, and Welfare," SAFE Working Paper No. 171.

Donadelli, M., M. Jüppner, M. Riedel, And C. Schlag (2017): "Temperature shocks and welfare costs," Journal of Economic Dynamics and Control, 82, 331-355.

Du, D., X. ZhaO, And R. Huang (2017): "The impact of climate change on developed economies," Economics Letters, 153, 43-46.

Epstein, L., AND S. Zin (1989): "Substitution, risk aversion, and the temporal behavior of consumption growth and asset returns: A theoretical framework," Econometrica, 57(4), 937969.

Fankhauser, S., And R. S. J. Tol (2005): "On climate change and economic growth," Resource and Energy Economics, 27(1), 1-17.

Fischer, C., And M. Springborn (2011): "Emissions targets and the real business cycle: Intensity targets versus caps or taxes," Journal of Environmental Economics and Management, $62(3), 352-366$.

Furlanetto, F., And M. Seneca (2014): "New perspectives on depreciation shocks as a source of business cycle fluctuations," Macroeconomic Dynamics, 18(6), 1209-1233.

Ganelli, G., And J. Tervala (2011): "International transmission of environmental policy: A New Keynesian perspective," Ecological Economics, 70(11), 2070-2082, Special Section Earth System Governance: Accountability and Legitimacy.

Gao, L., S. Hitzemann, I. Shaliastovich, And L. Xu (2016): "Oil volatility risk," Working $\underline{\text { Paper. }}$ 
Gillingham, K., R. G. Newell, And W. A. Pizer (2008): "Modeling endogenous technological change for climate policy analysis," Energy Economics, 30(6), 2734-2753.

Heutel, G. (2012): "How should environmental policy respond to business cycles? Optimal policy under persistent productivity shocks," Review of Economic Dynamics, 15(2), 244-264.

Jermann, U. J. (1998): "Asset pricing in production economies," Journal of Monetary Economics, 41, 257-275.

Kung, H., And L. Schmid (2015): "Innovation, growth, and asset prices," Journal of Finance, 70(3), 1001-1037.

Nordhaus, W. (2008): A question of balance: Weighing the options on global warming policies. Yale University Press.

UHLIG, H. (2007): "Explaining asset prices with external habits and wage rigidities in a DSGE model," American Economic Review, 97(2), 239-243.

van der Zwaan, B. C. C., R. Gerlagh, G. Klaassen, and L. Schrattenholzer (2002):

"Endogenous technological change in climate change modelling," Energy Economics, 24(1), $1-19$. 


\section{A Data}

Macro quantities. Annual growth rates of consumption (final consumption expenditure of households), output (gross domestic product - expenditure approach), and investment (gross fixed capital formation) for the G7 economies have been retrieved from the OECD National Accounts Statistics. Data on the gross domestic expenditure on R\&D (GERD) and on the business enterprise expenditure on R\&D (BERD) for the G7 economies and OECD group are from the OECD Main Science and Technology Indicators Dataset. Data on the share of government consumption in GDP are taken from the Penn World Table (PWT), version 8.0. All macroeconomic data are annual and run from 1975 to 2015 except for BERD and GERD data that are available for the period 1981-2015.

Asset prices. The equity market return for the G7 is obtained from the G7 (Market) Total Return Index provided by Datastream Global Equity Indices (DGEI). As proxy for the risk-free rate we use the G7 cross-country short-term interest rates average. Short-term interest rates are from the OECD Monthly Financial Statistics. Nominal rates are converted to real rates by using the "G7 Consumer Price Index (CPI) - all items", which is obtained from the OECD. Data are annual and run from 1975 to 2015.

Temperature. Data on global temperature (expressed in degrees Celsius) have been retrieved from the Climate Research Unit (University of East Anglia), i.e., from https://crudata.uea. ac.uk/cru/data/temperature/. Employed temperature data are annual and span the period from 1975 to 2015. Country-level temperatures (expressed in degrees Celsius) are obtained from the Climate Change Knowledge Portal (CCKP). Annual data are averages of monthly observations and span the period from 1981 to 2015. 


\section{B Additional Empirical Results}

Figure B.1: Impulse Response of R\&D Expenditure Growth to $\Delta T$
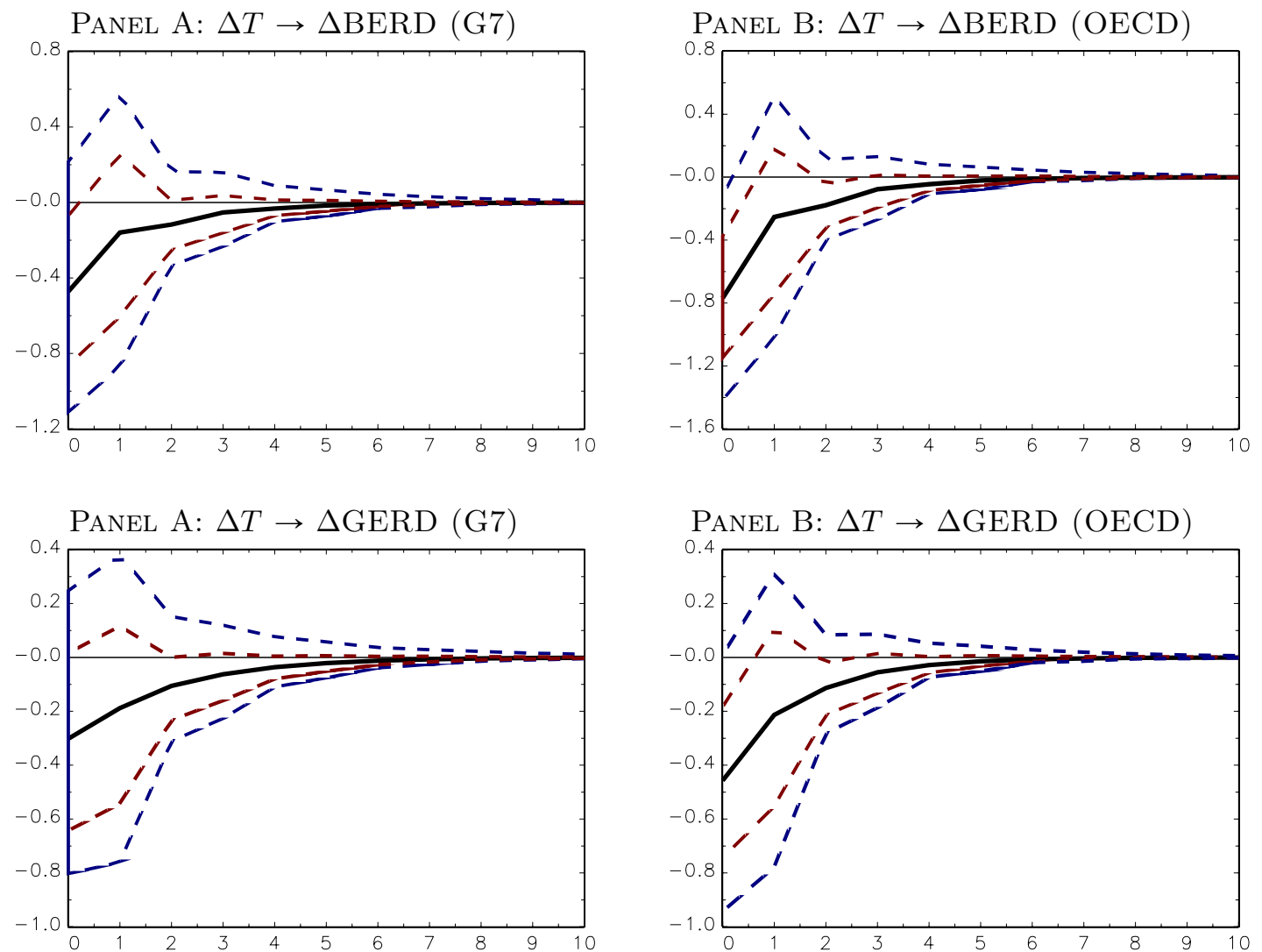

Notes: This figure presents Cholesky orthogonalized impulse responses of R\&D growth to a shock in the growth rate of global temperature. Impulse responses are obtained by estimating a bi-variate VAR(1) where global temperature is ordered first. A constant is included. Solid black lines: estimated impulse responses. Dashed blue lines: $90 \%$ bootstrapped confidence bands. Dashed red lines: $68 \%$ bootstrapped confidence bands. The growth rates of BERD and GERD for the G7 and OECD are from the OECD Main Science and Technology Indicators Database. Data on Global temperature (expressed in degrees Celsius) are from the Climate Research Unit. Data are annual and span the period from 1981 to 2015. 
Table B.I: Effects of Rising Temperature on R\&D Expenditure: ControlLing FOR The Global FinAnCial CRisis

\begin{tabular}{|c|c|c|c|}
\hline \multicolumn{4}{|c|}{ Panel A: R\&D vs Global Temperature } \\
\hline & G7 & OECD & $\mathrm{OECD}+$ \\
\hline Regressor & (1) & $(2)$ & $(3)$ \\
\hline$\triangle B E R D(-1)$ & $\begin{array}{c}0.37 * * * \\
(0.000)\end{array}$ & $\begin{array}{c}0.06 \\
(0.568)\end{array}$ & $\begin{array}{c}0.09 \\
(0.359)\end{array}$ \\
\hline$T_{G}$ & $\begin{array}{l}-0.70^{*} \\
(0.051)\end{array}$ & $\begin{array}{c}-2.15^{* * * *} \\
(0.002)\end{array}$ & $\begin{array}{l}-1.64^{* *} \\
(0.021)\end{array}$ \\
\hline Crisis & $\begin{array}{c}-3.52^{* * *} \\
(0.002)\end{array}$ & $\begin{array}{c}-5.09^{* * *} \\
(0.001)\end{array}$ & $\begin{array}{c}-5.20^{* * *} \\
(0.000)\end{array}$ \\
\hline$\triangle G E R D(-1)$ & $\begin{array}{c}0.38 * * * \\
(0.000)\end{array}$ & $\begin{array}{c}0.18^{* * *} * \\
(0.003)\end{array}$ & $\begin{array}{c}0.25^{* * * *} \\
(0.000)\end{array}$ \\
\hline$T_{G}$ & $\begin{array}{l}-0.50 * * \\
(0.013)\end{array}$ & $\begin{array}{r}-0.67 * * \\
(0.025)\end{array}$ & $\begin{array}{c}-0.35 \\
(0.345)\end{array}$ \\
\hline Crisis & $\begin{array}{l}-1.19 * \\
(0.074)\end{array}$ & $\begin{array}{c}-3.27 * * * \\
(0.006)\end{array}$ & $\begin{array}{c}-3.57^{* * *} \\
(0.001)\end{array}$ \\
\hline \multicolumn{4}{|c|}{ Panel B: R\&D vs Country-specific Temperature } \\
\hline & G7 & OECD & $\mathrm{OECD}+$ \\
\hline Regressor & $(1)$ & $(2)$ & $(3)$ \\
\hline$\triangle B E R D(-1)$ & $\begin{array}{c}0.40 * * * \\
(0.000)\end{array}$ & $\begin{array}{c}0.06 \\
(0.516)\end{array}$ & $\begin{array}{c}0.09 \\
(0.362)\end{array}$ \\
\hline$T_{i}$ & $\begin{array}{c}-0.33 \\
(0.152)\end{array}$ & $\begin{array}{c}-0.46 \\
(0.293)\end{array}$ & $\begin{array}{c}-0.25 \\
(0.559)\end{array}$ \\
\hline Crisis & $\begin{array}{c}-3.83^{* * *} \\
(0.001)\end{array}$ & $\begin{array}{c}-5.49 * * * \\
(0.001)\end{array}$ & $\begin{array}{c}-5.55^{* * *} \\
(0.000)\end{array}$ \\
\hline$\Delta G E R D(-1)$ & $\begin{array}{c}0.40 * * * \\
(0.000)\end{array}$ & $\begin{array}{c}0.18^{* * *} * \\
(0.003)\end{array}$ & $\begin{array}{c}0.23 * * * \\
(0.000)\end{array}$ \\
\hline$T_{i}$ & $\begin{array}{c}-0.32 \\
(0.164)\end{array}$ & $\begin{array}{c}-0.26 \\
(0.328)\end{array}$ & $\begin{array}{c}-0.05 \\
(0.854)\end{array}$ \\
\hline Crisis & $\begin{array}{c}-1.40^{* *} \\
(0.040)\end{array}$ & $\begin{array}{c}-3.36^{* * *} \\
(0.004)\end{array}$ & $\begin{array}{c}-3.48^{* * *} \\
(0.001)\end{array}$ \\
\hline
\end{tabular}

Notes: This table presents predictability evidence for R\&D growth. Panel A reports the estimated coefficients on average annual temperature from a panel regression of BERD (GERD) growth rate, $\triangle B E R D_{i, t}\left(\triangle G E R D_{i, t}\right)$ on its lagged value, global temperature, $T_{G}$, and a dummy variable which equals one for the years 2008 and 2009, capturing the negative effects of the global financial crisis. Panel B report the estimated coefficients on average annual temperature from a panel regression of BERD (GERD) growth rate, $\triangle B E R D_{i, t}\left(\Delta G E R D_{i, t}\right)$ on its lagged value, country-specific temperature, $T_{i}$, and a dummy variable, Crisis, which equals one for the years 2008 and 2009, capturing the negative effects of the global financial crisis. In column (1), models are estimated on data for the G7 countries while in column (2) and (3) we use data for the full OECD group and all OECD members plus seven additional countries (Argentina, China, Romania, Russia, Singapore, South Africa, and Chinese Taipei), respectively. Robust standard errors are computed by clustering standard errors at the country level. The p-values are reported in round brackets. The growth rate of BERD (GERD) for the G7 and OECD are from the OECD Main Science and Technology Indicators Database. Data on Global temperature (expressed in degrees Celsius) are from the Climate Research Unit. Countries' annual average temperatures (expressed in degrees Celsius) are from the Climate Change Knowledge Portal (CCKP). Temperature data are not available for Romania and Chinese Taipei. The sample is $1981-2015$. ***, **, and * denote significance at the $1 \%, 5 \%$, and $10 \%$ level, respectively. 
Table B.II: Effects of Rising Temperature on R\&D Expenditure: Different Country Groups

\begin{tabular}{|c|c|c|}
\hline \multicolumn{3}{|c|}{ Panel A: Developed vs Developing Countries } \\
\hline & Developed & Developing \\
\hline Regressor & $(1)$ & $(2)$ \\
\hline$\triangle B E R D(-1)$ & $\begin{array}{c}0.03 \\
(0.795)\end{array}$ & $\begin{array}{c}0.20 * * * \\
(0.000)\end{array}$ \\
\hline$T_{G}$ & $\begin{array}{l}-1.48^{* *} \\
(0.030)\end{array}$ & $\begin{array}{l}-8.10 \\
(0.285)\end{array}$ \\
\hline$\triangle G E R D(-1)$ & $\begin{array}{c}0.24^{* * *} \\
(0.000)\end{array}$ & $\begin{array}{c}0.21 \\
(0.223)\end{array}$ \\
\hline$T_{G}$ & $\begin{array}{l}-0.46 \\
(0.225)\end{array}$ & $\begin{array}{c}0.92 \\
(0.125)\end{array}$ \\
\hline \multicolumn{3}{|c|}{ Panel B: Northern ("cooler") vs southern ("warmer") countries } \\
\hline & North & South \\
\hline Regressor & $(1)$ & $(2)$ \\
\hline$\triangle B E R D(-1)$ & $\begin{array}{c}0.00 \\
(0.994)\end{array}$ & $\begin{array}{c}0.23^{* * *} \\
(0.000)\end{array}$ \\
\hline$T_{G}$ & $\begin{array}{l}-1.52^{*} \\
(0.056)\end{array}$ & $\begin{array}{l}-2.15 \\
(0.162)\end{array}$ \\
\hline$\Delta G E R D(-1)$ & $\begin{array}{c}0.22^{* * *} \\
(0.001)\end{array}$ & $\begin{array}{c}0.34^{* * *} \\
(0.002)\end{array}$ \\
\hline$T_{G}$ & $\begin{array}{c}-0.28 \\
(0.540)\end{array}$ & $\begin{array}{c}-0.82^{* * *} \\
(0.007)\end{array}$ \\
\hline
\end{tabular}

Notes: This table presents predictability evidence for R\&D growth. Panel A and B report the estimated coefficients on average annual temperature from a panel regression of BERD (GERD) growth rate, $\triangle B E R D_{i, t}\left(\triangle G E R D_{i, t}\right)$ on its lagged value and global temperature, $T_{G}$. In Panel $\mathrm{A}$, we use data for the OECD + countries and divide the sample according to the global north vs. global south divide. In column (1), models are estimated on developed countries while in column (2) we use data for developing countries. The group of developing countries ("global south") comprises Argentina, Chile, China, Mexico, and South Africa while the group of developed countries ("global north") includes all the remaining countries. In Panel B, we divide the OECD + countries into warmer and cooler countries. In column (1), models are estimated on northern ("cooler") countries while in column (2) we use data for southern ("warmer") countries. The latter group comprises Argentina, Australia, Chile, China, Chinese Taipei, Greece, Italy, Mexico, Portugal, Spain, and South Africa. The former group includes all the remaining countries. Robust standard errors are computed by clustering standard errors at the country level. The p-values are reported in round brackets. The growth rate of BERD (GERD) for the G7 and OECD are from the OECD Main Science and Technology Indicators Database. Data on Global temperature (expressed in degrees Celsius) are from the Climate Research Unit. The sample is $1981-2015 . * * *, * *$, and ${ }^{*}$ denote significance at the $1 \%, 5 \%$, and $10 \%$ level, respectively. 
Figure B.2: Impulse Response of R\&D Expenditure Growth to $\Delta T$
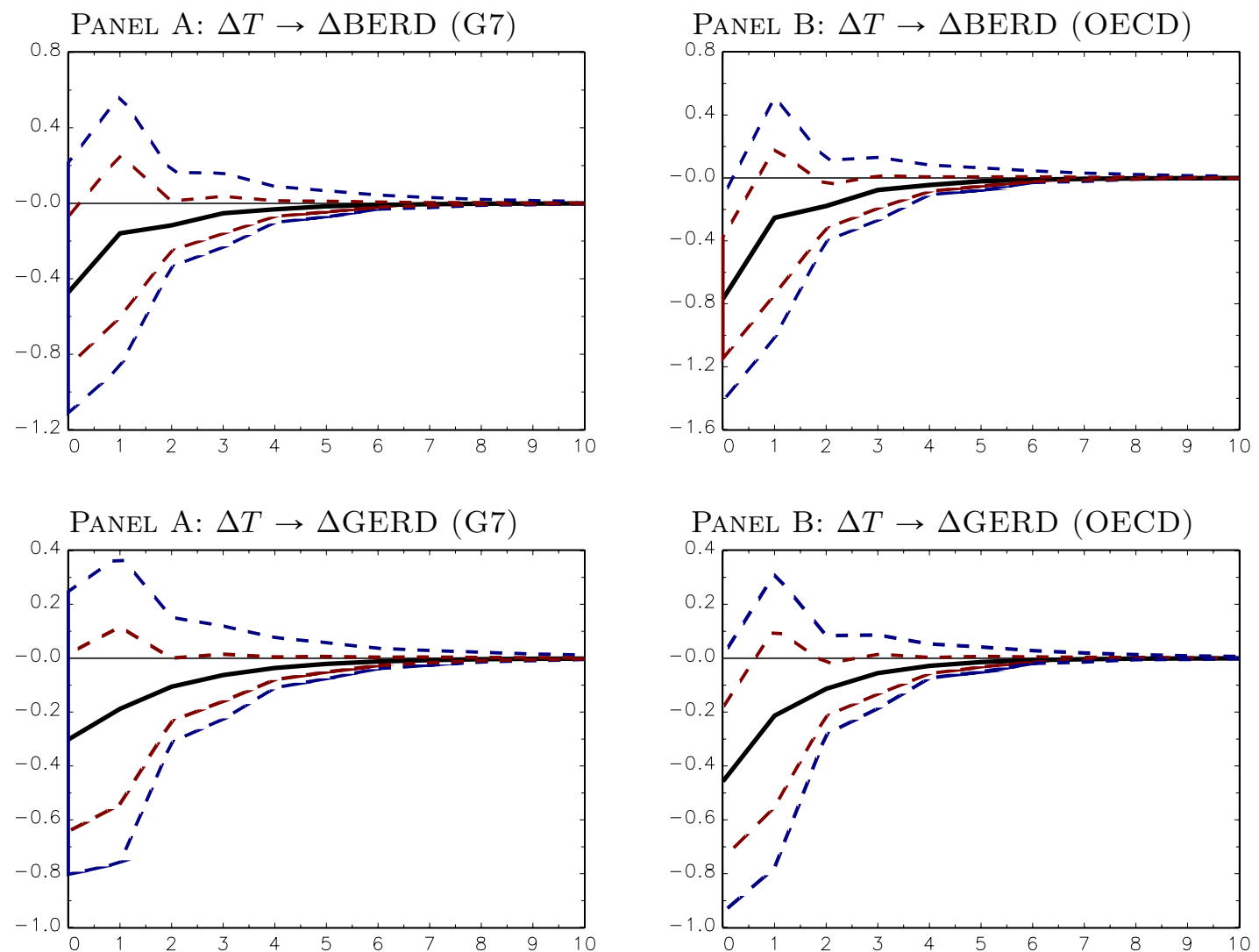

Notes: This figure presents Cholesky orthogonalized impulse responses of R\&D growth to a shock in the growth rate of global temperature. Impulse responses are obtained by estimating a bi-variate $\operatorname{VAR}(1)$ where global temperature is ordered first. A constant is included. Solid black lines: estimated impulse responses. Dashed blue lines: $90 \%$ bootstrapped confidence bands. Dashed red lines: $68 \%$ bootstrapped confidence bands. The growth rates of BERD and GERD for the G7 and OECD are from the OECD Main Science and Technology Indicators Database. Data on Global temperature (expressed in degrees Celsius) are from the Climate Research Unit. Data are annual and span the period from 1981 to 2015 .

\section{Additional Quantitative Results}

This appendix reports additional quantitative results, based on variations of the benchmark model.

\section{C.1 Investment subsidies}

Table C.I reports the simulated moments of the economy incorporating investment subsidies that offset the welfare costs caused by temperature shocks. 
Table C.I: Simulated Moments: Investment Subsidies

\begin{tabular}{|c|c|c|c|}
\hline Variable & Data & Benchmark & $\tau_{i}=0.222$ \\
\hline & & [1] & {$[2]$} \\
\hline \multicolumn{4}{|c|}{ MACRO QUANTITIES } \\
\hline $\mathbb{E}(\Delta c)$ & 2.25 & 2.21 & 2.28 \\
\hline$\sigma(\Delta y)$ & 1.60 & 1.62 & 1.63 \\
\hline$\sigma(\Delta c)$ & 1.20 & 1.01 & 1.03 \\
\hline$\sigma(\Delta c) / \sigma(\Delta y)$ & 0.75 & 0.62 & 0.63 \\
\hline$\sigma\left(\Delta i^{*}\right) / \sigma(\Delta y)$ & 2.05 & 1.03 & 1.07 \\
\hline$\sigma(\Delta s) / \sigma(\Delta y)$ & 1.92 & 2.14 & 2.13 \\
\hline$\rho(\Delta c, \Delta y)$ & 0.87 & 0.37 & 0.35 \\
\hline$\rho\left(\Delta c, \Delta i^{*}\right)$ & 0.81 & 0.26 & 0.16 \\
\hline$\rho\left(\Delta i^{*}, \Delta y\right)$ & 0.93 & 0.99 & 0.97 \\
\hline$\rho(\Delta s, \Delta y)$ & 0.59 & 0.97 & 0.97 \\
\hline$\rho(\Delta s, T)$ & -0.46 & -0.10 & -0.10 \\
\hline \multicolumn{4}{|c|}{ TEMPERATURE } \\
\hline $\mathbb{E}(T)$ & 14.27 & 14.27 & 14.27 \\
\hline$\sigma(T)$ & 0.23 & 0.23 & 0.23 \\
\hline \multicolumn{4}{|c|}{ ASSET PRICES } \\
\hline $\mathbb{E}\left(R^{f}\right)$ & 2.38 & 2.31 & 2.31 \\
\hline$\sigma\left(R^{f}\right)$ & 2.88 & 0.25 & 0.25 \\
\hline $\mathbb{E}\left[R_{e x}^{L E V}\right]$ & 5.72 & 1.68 & 1.85 \\
\hline$\sigma\left(R_{e x}^{L E V}\right)$ & 14.72 & 4.83 & 4.99 \\
\hline
\end{tabular}

Notes: This table reports the main moments for the benchmark calibration (specification [1]) and the model with a investment subsidy rate of $22.1 \%$ that offsets welfare costs of temperature risk (specification [2]). The aggregate market return is levered as in Croce (2014). Models' entries are obtained from repetitions of small-sample simulations (i.e., averages over 1000 simulations of 41 years). $\mathbb{E}[\cdot], \sigma(\cdot)$ and $\rho(\cdot, \cdot)$ denote mean, volatility, and correlation, respectively. Means and standard deviations are expressed in percentage points. Data on Global temperature and G7 macro-aggregates are from the Climate Research Unit and the OECD, respectively. Data are annual and run from 1975 (or later) to 2015. Additional details on the data are provided in Appendix A.

\section{C.2 Tax smoothing policy}

If the government is not committed to a zero-deficit rule, the new government budget constraint becomes:

$$
G_{t}+R_{f, t-1} B_{t-1}=\tau_{l, t} W_{t}^{u} L_{t}+\tau_{\pi} N_{t} \Pi_{t}+B_{t}
$$

where the government has an additional instrument to finance its public spending. Besides using taxes on labor and profits, it can issue public debt $B_{t}$ and thus run budget deficits. We assume that the debt-output ratio follows the process:

$$
\frac{B_{t}}{Y_{t}}=\rho_{b} \frac{B_{t-1}}{Y_{t-1}}+\phi_{b}\left(\ln \left(L_{s s}\right)-\ln \left(L_{t}\right)\right),
$$

where $\rho_{b} \in(0,1)$ captures the delay of debt repayment, $\phi_{b} \geqslant 0$ is a scale parameter, and $L_{s s}$ is the steady-state level of labor. This implies that the labor tax rate is determined by:

$$
\tau_{l, t}=\tau_{l, t}^{0}+\frac{Y_{t}}{W_{t}^{u} L_{t}}\left[\left(\frac{R_{f, t-1}}{Y_{t} / Y_{t-1}}-\rho_{b}\right) \frac{B_{t-1}}{Y_{t-1}}+\phi_{b}\left(\ln \left(L_{t}\right)-\ln \left(L_{s s}\right)\right)\right],
$$


where $\tau_{l, t}^{0}$ is the zero-deficit tax rate as in Equation (31). Following Croce, Nguyen, and Schmid (2014) we use an employment-oriented tax rule and set $\phi_{b}>0$. In bad times when labor falls below the steady state level, the government cuts taxes on labor income (i.e. increases debt), whereas in good times (booms), it increases taxes (i.e. reduces debt). Note that the second term on the right-hand side of Equation (C.3) accounts also for the long-lasting effect on taxes caused by debt repayment and that by imposing $\rho_{b} \in(0,1)$ we rule out unstable fluctuations of the debt-output ratio. In line with the calibration reported in Croce, Nguyen, and Schmid (2013), we set the intensity of the smoothing policy, $\phi_{b}$, and the related the inverse of the speed of debt repayment, $\rho_{b}$, to values of 0.025 and $\sqrt[4]{0.975}$, respectively.

Given that the households holds government bonds, $B_{t}$, the new budget constraint of the representative household becomes:

$$
C_{t}+B_{t}=\left(1-\tau_{l, t}\right) W_{t}^{u} L_{t}+R_{f, t-1} B_{t-1}+D_{a, t}-S_{t}
$$

The simulated moments using the just described fiscal rule are reported in Table C.II, the corresponding welfare implications are reported in Table C.III, and the corresponding long-run output growth losses in Table C.IV. 
Table C.II: Simulated Moments: A Different Tax Regime

\begin{tabular}{|c|c|c|c|c|}
\hline Variable & Data & Benchmark & $\tau_{T}<0$ & $\tau_{T}=0$ \\
\hline & & {$[1]$} & {$[2]$} & {$[3]$} \\
\hline \multicolumn{5}{|c|}{ MACRO QUANTITIES } \\
\hline $\mathbb{E}(\Delta c)$ & 2.25 & 2.21 & 2.21 & 2.21 \\
\hline$\sigma(\Delta y)$ & 1.60 & 1.60 & 1.62 & 1.60 \\
\hline$\sigma(\Delta c)$ & 1.20 & 1.01 & 1.01 & 0.94 \\
\hline$\sigma(\Delta c) / \sigma(\Delta y)$ & 0.75 & 0.62 & 0.62 & 0.59 \\
\hline$\sigma\left(\Delta i^{*}\right) / \sigma(\Delta y)$ & 2.05 & 1.03 & 1.03 & 1.02 \\
\hline$\sigma(\Delta s) / \sigma(\Delta y)$ & 1.92 & 2.14 & 2.14 & 2.14 \\
\hline$\rho(\Delta c, \Delta y)$ & 0.87 & 0.37 & 0.36 & 0.40 \\
\hline$\rho\left(\Delta c, \Delta i^{*}\right)$ & 0.81 & 0.26 & 0.26 & 0.32 \\
\hline$\rho\left(\Delta i^{*}, \Delta y\right)$ & 0.93 & 0.99 & 0.99 & 0.99 \\
\hline$\rho(\Delta s, \Delta y)$ & 0.59 & 0.97 & 0.97 & 0.97 \\
\hline$\rho(\Delta s, T)$ & -0.46 & -0.10 & -0.10 & 0.00 \\
\hline \multicolumn{5}{|c|}{ TEMPERATURE } \\
\hline $\mathbb{E}(T)$ & 14.27 & 14.27 & 14.27 & 14.27 \\
\hline$\sigma(T)$ & 0.23 & 0.23 & 0.23 & 0.23 \\
\hline \multicolumn{5}{|c|}{ ASSET PRICES } \\
\hline $\mathbb{E}\left(R^{f}\right)$ & 2.31 & 2.31 & 2.31 & 2.35 \\
\hline$\sigma\left(R^{f}\right)$ & 2.88 & 0.25 & 0.25 & 0.22 \\
\hline $\mathbb{E}\left[R_{e x}^{L E V}\right]$ & 5.72 & 1.68 & 1.68 & 1.51 \\
\hline$\sigma\left(R_{e x}^{L E V}\right)$ & 14.72 & 4.83 & 4.84 & 4.70 \\
\hline
\end{tabular}

Notes: This table reports the main moments for the benchmark calibration (specification [1]), the main moments for the model with the tax-smoothing policy in place and temperature risk, i.e., $\tau_{T}<0$ in Equation (23) (specification [2]), and the model with the tax-smoothing policy in place but where temperature does not affect the obsolescence rate of patents (specification [3]), i.e., $\tau_{T}=0$ in Equation (23). In specifications [2] and [3], the government is allowed to run a budget deficit according to the equations in Section C.2. The aggregate market return is levered as in Croce (2014). Models' entries are obtained from repetitions of small-sample simulations (i.e., averages over 1000 simulations of 41 years). $\mathbb{E}[\cdot]$, $\sigma(\cdot)$ and $\rho(\cdot, \cdot)$ denote mean, volatility, and correlation, respectively. Means and standard deviations are expressed in percentage points. Data on Global temperature and G7 macro-aggregates are from the Climate Research Unit and the OECD, respectively. Data are annual and run from 1975 (or later) to 2015. Additional details on the data are provided in Appendix A.

Table C.III: Welfare Costs of Temperature Risk: A Different Tax Regime

\begin{tabular}{ccc}
\hline \hline & {$\left[\tau_{T}=0\right]$} & {$\left[\tau_{T}=-0.007125\right]$} \\
\hline $\mathbb{E}(\hat{U})$ & 0.9772 & 0.8799 \\
$\Delta$ & - & $11.06 \%$ \\
\hline \hline
\end{tabular}

Notes: This table reports the welfare costs of temperature shocks when the government is allowed to run a budget deficit. Welfare costs are defined as the percentage increase $\Delta>0$ in time-zero utility bundle units that the household should receive in order to be indifferent between living in an economy with full risk exposure (i.e., $\sigma_{T}, \sigma_{a}, \sigma_{g}>0$ ) and an economy without temperature effects. Temperature effects are eliminated by imposing $\tau_{T}=0$. 
Table C.IV: Long-Run Effects of Temperature Shocks: A Different Tax REGIME

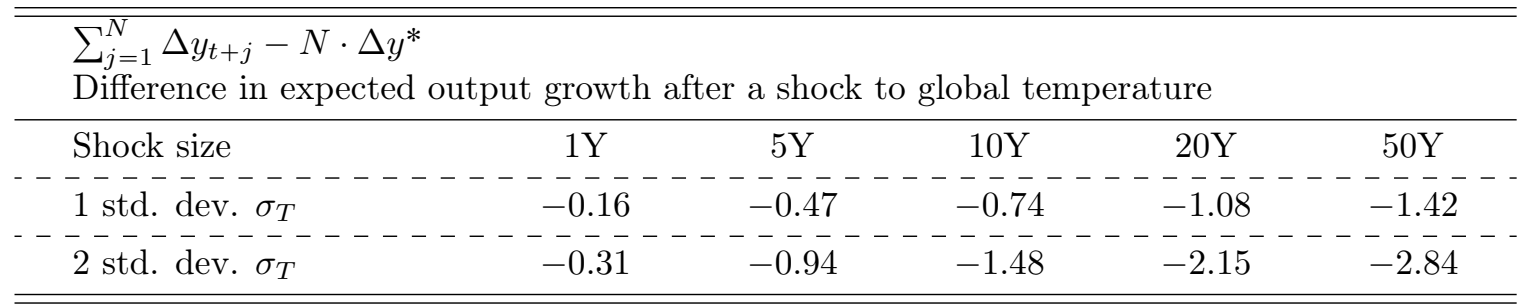

Notes: This table reports the cumulative change in output growth over 1, 5, 10,20, and 50 years in percentage points after a temporary temperature shock for the specification where the government is allowed to run a budget deficit. The cumulative growth in an economy without such a shock is compared to that in an economy with shocks to temperature, $z_{t}$. Specifically, we report $\left(\sum_{j=1}^{N} \Delta y_{t+j}\right)-N \cdot \Delta y^{*}$ where $\Delta y_{t+j}$ is the log growth rate of total output, and $\Delta y^{*}$ is the steady state growth rate in the economy without a shock (i.e., with $\varepsilon_{T}=0$ ). For example, the entry -0.46 for a horizon of 5 years in the first row means that cumulative output growth over these 5 years has been 0.46 percentage points lower than it would have been without the temperature shock. The amount of lost output growth is reported for temperature shocks amounting to one and two standard deviations, i.e., to $0.12^{\circ} \mathrm{C}$ and $0.24^{\circ} \mathrm{C}$, respectively.

\section{C.3 Decreasing role of $\mathrm{R} \& \mathrm{D}$}

Table C.V: Simulated Moments: Decreasing Role of R\&D

\begin{tabular}{|c|c|c|c|c|}
\hline Variable & Data & Benchmark & $\xi=0.3$ and $\tau_{T}<0$ & $\xi=0.3$ and $\tau_{T}=0$ \\
\hline & & [1] & {$[2]$} & {$[3]$} \\
\hline \multicolumn{5}{|c|}{ MACRO QUANTITIES } \\
\hline $\mathbb{E}(\Delta c)$ & 2.25 & 2.21 & 2.10 & 2.10 \\
\hline$\sigma(\Delta y)$ & 1.60 & 1.62 & 1.39 & 1.38 \\
\hline$\sigma(\Delta c)$ & 1.20 & 1.01 & 0.97 & 0.93 \\
\hline$\sigma(\Delta c) / \sigma(\Delta y)$ & 0.75 & 0.62 & 0.70 & 0.67 \\
\hline$\sigma\left(\Delta i^{*}\right) / \sigma(\Delta y)$ & 2.05 & 1.03 & 1.04 & 1.03 \\
\hline$\sigma(\Delta s) / \sigma(\Delta y)$ & 1.92 & 2.14 & 2.25 & 2.24 \\
\hline$\rho(\Delta c, \Delta y)$ & 0.87 & 0.37 & 0.84 & 0.86 \\
\hline$\rho\left(\Delta c, \Delta i^{*}\right)$ & 0.81 & 0.26 & 0.78 & 0.85 \\
\hline$\rho\left(\Delta i^{*}, \Delta y\right)$ & 0.93 & 0.99 & 0.99 & 1.00 \\
\hline$\rho(\Delta s, \Delta y)$ & 0.59 & 0.97 & 0.96 & 0.97 \\
\hline$\rho(\Delta s, T)$ & -0.46 & -0.10 & -0.10 & 0.00 \\
\hline \multicolumn{5}{|c|}{ TEMPERATURE } \\
\hline $\mathbb{E}(T)$ & 14.27 & 14.27 & 14.27 & 14.27 \\
\hline$\sigma(T)$ & 0.23 & 0.23 & 0.23 & 0.23 \\
\hline \multicolumn{5}{|c|}{ ASSET PRICES } \\
\hline $\mathbb{E}\left(r_{f}\right)$ & 2.38 & 2.31 & 2.36 & 2.39 \\
\hline$\sigma\left(r_{f}\right)$ & 2.88 & 0.25 & 0.22 & 0.19 \\
\hline $\mathbb{E}\left[r_{a}-r_{f}\right]$ & 5.72 & 1.68 & 1.21 & 1.05 \\
\hline$\sigma\left(r_{a}-r_{f}\right)$ & 14.72 & 4.83 & 4.12 & 3.99 \\
\hline
\end{tabular}

Notes: This table reports the main moments for the benchmark calibration (specification [1]) and two other model specifications. In models [2] and [3], intermediate goods enter the production function with a smaller share compared to the benchmark economy (and a higher monopoly markup is required due to the balanced growth restriction), i.e., $\xi=0.3$ (and $\nu=1 / 2.5167$ ) vs. $\xi=0.57$ (and $\nu=1 / 1.5$ ). In specification [1] and [2], temperature affects the obsolescence rate of patents, i.e., $\tau_{T}<0$ in Equation (23) while in specification [3], temperature effects are offset, i.e, $\tau_{T}=0$. The aggregate market return is levered as in Croce (2014). Models' entries are obtained from repetitions of small-sample simulations (i.e., averages over 1000 simulations of 41 years). $\mathbb{E}[\cdot], \sigma(\cdot)$ and $\rho(\cdot, \cdot)$ denote mean, volatility, and correlation, respectively. Means and standard deviations are expressed in percentage points. Data on Global temperature and G7 macro-aggregates are from the Climate Research Unit and the OECD, respectively. Data are annual and run from 1975 (or later) to 2015. Additional details on the data are provided in Appendix A. 
Table C.Vi: Welfare Costs of Temperature Risk: Decreasing Role of R\&D

\begin{tabular}{ccc}
\hline \hline & {$\left[\tau_{T}=0\right]$} & {$\left[\tau_{T}=-0.007125\right]$} \\
\hline $\mathbb{E}(\hat{U})$ & 3.3998 & 3.0778 \\
$\Delta$ & - & $10.46 \%$ \\
\hline \hline
\end{tabular}

Notes: This table reports the welfare costs of temperature shocks for the specification where intermediate goods enter the production function with a smaller share compared to the benchmark economy, i.e., $\xi=0.3$. Due to the balanced growth restriction, we also need to impose a higher monopoly markup compared to the benchmark economy, i.e., $\nu=1 / 2.5167$. Welfare costs are defined as the percentage increase $\Delta>0$ in time-zero utility bundle units that the household should receive in order to be indifferent between living in an economy with full risk exposure (i.e., $\sigma_{T}, \sigma_{a}, \sigma_{g}>0$ ) and an economy without temperature effects. Temperature effects are eliminated by imposing $\tau_{T}=0$.

\section{Table C.VII: Long-Run Effects of Temperature Shocks: Decreasing Role oF R\&D}

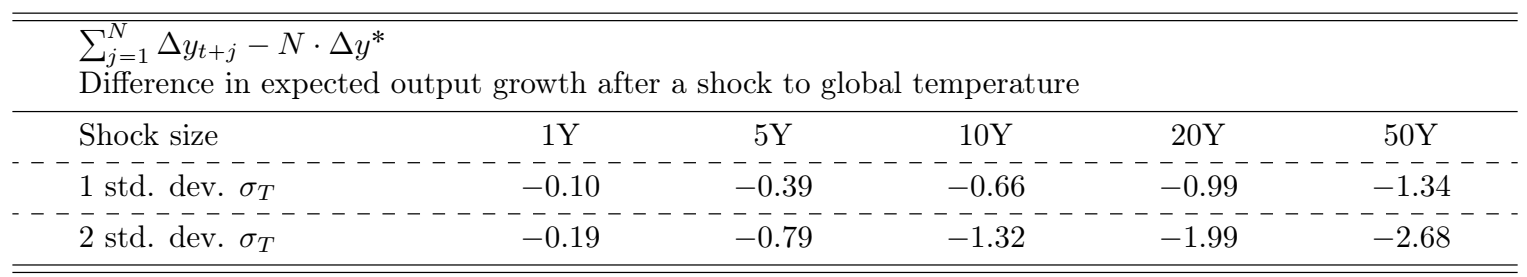

Notes: This table reports the cumulative change in output growth over 1, 5, 10, 20, and 50 years in percentage points after a temporary temperature shock for the specification where intermediate goods enter the production function with a smaller share compared to the benchmark economy, i.e., $\xi=0.3$. Due to the balanced growth restriction, we also need to impose a higher monopoly markup compared to the benchmark economy, i.e., $\nu=1 / 2.5167$. The cumulative growth in an economy without such a shock is compared to that in an economy with shocks to temperature, $z_{t}$. Specifically, we report $\left(\sum_{j=1}^{N} \Delta y_{t+j}\right)-N \cdot \Delta y^{*}$ where $\Delta y_{t+j}$ is the log growth rate of total output, and $\Delta y^{*}$ is the steady state growth rate in the economy without a shock (i.e., with $\varepsilon_{T}=0$ ). For example, the entry -0.46 for a horizon of 5 years in the first row means that cumulative output growth over these 5 years has been 0.46 percentage points lower than it would have been without the temperature shock. The amount of lost output growth is reported for temperature shocks amounting to one and two standard deviations, i.e., to $0.12^{\circ} \mathrm{C}$ and $0.24^{\circ} \mathrm{C}$, respectively.

\section{Figure C.1: Welfare Costs of Global Temperature Risk vs. $\tau_{i}$ : Decreasing ROLE OF R\&D}

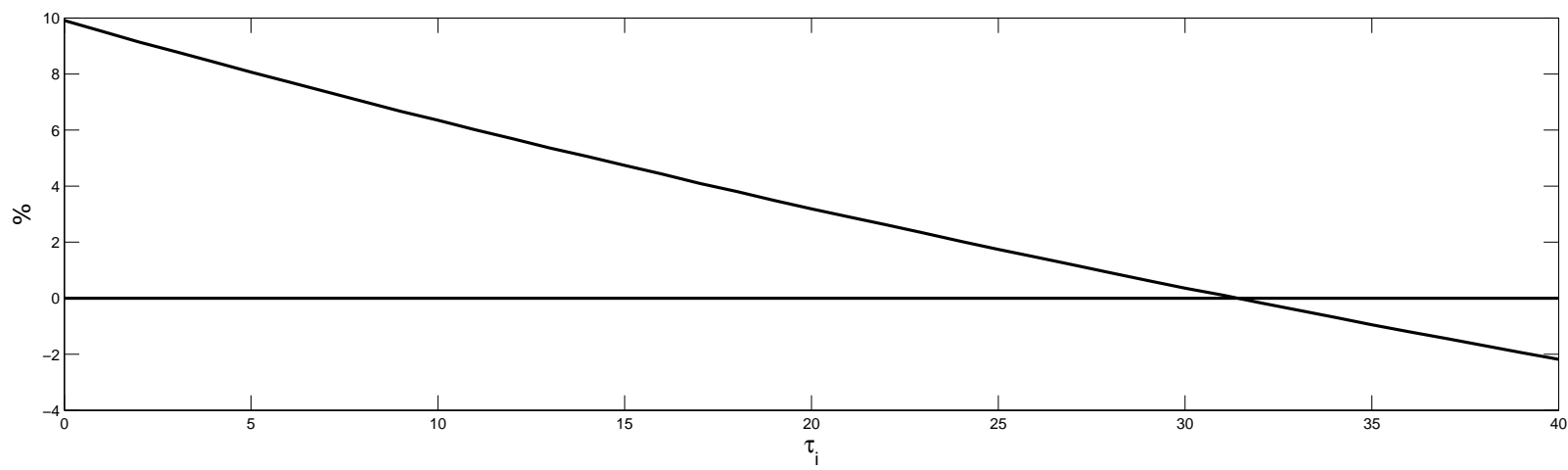

Notes: This figure reports welfare costs for different values of the capital investment subsidy rate, $\tau_{i}$, for the specification where intermediate goods enter the production function with a smaller share compared to the benchmark economy, i.e., $\xi=0.3$. Due to the balanced growth restriction, we also need to impose a higher monopoly markup compared to the benchmark economy, i.e., $\nu=1 / 2.5167$. Welfare costs are computed as in Equation (38). All the remaining parameters are set to the values reported in Table II. 


\section{C.4 Different temperature risk}

In the benchmark model, positive unexpected temperature shocks affects the depreciation rate of patents negatively, i.e., by decreasing $\kappa_{t}$. In this section, we report the simulated moments and welfare costs when, instead of unexpected temperature shocks, deviations of temperature from the long-run mean affects patent obsolescence. Hence, Equation (23) is changed to the following one:

$$
\theta_{t}=\tau_{T}\left(T_{t}-\mu_{T}\right)
$$

The parameter $\tau_{T}$ is re-calibrated to match the empirically observed decrease of $0.6 \mathrm{pp}$ in $\mathrm{R} \& \mathrm{D}$ expenditures in response to a positive temperature shock. In particular, we find $\tau_{T}=-0.00901$ to deliver the desired impulse response function in the model. Table C.VIII reports the simulated moments, Table C.IX the associated welfare costs of temperature shocks, and Table C.X the lost output after a single temperature shock in this model specification.

Table C.ViIi: Simulated Moments: Different Temperature Risk

\begin{tabular}{|c|c|c|c|c|}
\hline Variable & Data & Benchmark & $\tau_{T}<0$ & $\tau_{T}=0$ \\
\hline & & {$[1]$} & {$[2]$} & {$[3]$} \\
\hline \multicolumn{5}{|c|}{ MACRO QUANTITIES } \\
\hline $\mathbb{E}(\Delta c)$ & 2.25 & 2.21 & 2.19 & 2.21 \\
\hline$\sigma(\Delta y)$ & 1.60 & 1.62 & 1.62 & 1.60 \\
\hline$\sigma(\Delta c)$ & 1.20 & 1.01 & 1.00 & 0.93 \\
\hline$\sigma(\Delta c) / \sigma(\Delta y)$ & 0.75 & 0.62 & 0.62 & 0.58 \\
\hline$\sigma\left(\Delta i^{*}\right) / \sigma(\Delta y)$ & 2.05 & 1.03 & 1.03 & 1.02 \\
\hline$\sigma(\Delta s) / \sigma(\Delta y)$ & 1.92 & 2.14 & 2.15 & 2.14 \\
\hline$\rho(\Delta c, \Delta y)$ & 0.87 & 0.37 & 0.37 & 0.40 \\
\hline$\rho\left(\Delta c, \Delta i^{*}\right)$ & 0.81 & 0.26 & 0.27 & 0.33 \\
\hline$\rho\left(\Delta i^{*}, \Delta y\right)$ & 0.93 & 0.99 & 0.99 & 0.99 \\
\hline$\rho(\Delta s, \Delta y)$ & 0.59 & 0.97 & 0.97 & 0.97 \\
\hline$\rho(\Delta s, T)$ & -0.46 & -0.10 & -0.08 & 0.00 \\
\hline \multicolumn{5}{|c|}{ TEMPERATURE } \\
\hline $\mathbb{E}(T)$ & 14.27 & 14.27 & 14.27 & 14.27 \\
\hline$\sigma(T)$ & 0.23 & 0.23 & 0.23 & 0.23 \\
\hline \multicolumn{5}{|c|}{ ASSET PRICES } \\
\hline $\mathbb{E}\left(r_{f}\right)$ & 2.38 & 2.31 & 2.32 & 2.34 \\
\hline$\sigma\left(r_{f}\right)$ & 2.88 & 0.25 & 0.24 & 0.22 \\
\hline $\mathbb{E}\left[r_{a}-r_{f}\right]$ & 5.72 & 1.68 & 1.58 & 1.51 \\
\hline$\sigma\left(r_{a}-r_{f}\right)$ & 14.72 & 4.83 & 4.76 & 4.69 \\
\hline
\end{tabular}

Notes: This table reports the main moments for the benchmark calibration (specification [1]) and two other model specifications. In models [2] and [3], temperature risk affects the macro economy differently than in the benchmark model. In specification [1], temperature affects the obsolescence rate of patents, i.e., as in Equation $(23)$ with $\tau_{T}=-0.007125$, in specification [2] as in Equation (C.5) with $\tau_{T}=-0.00901$, while in specification [3], temperature effects are shut down, i.e, $\tau_{T}=0$. The aggregate market return is levered as in Croce (2014). Models' entries are obtained from repetitions of small-sample simulations (i.e., averages over 1000 simulations of 41 years). $\mathbb{E}[\cdot], \sigma(\cdot)$ and $\rho(\cdot, \cdot)$ denote mean, volatility, and correlation, respectively. Means and standard deviations are expressed in percentage points. Data on Global temperature and G7 macro-aggregates are from the Climate Research Unit and the OECD, respectively. Data are annual and run from 1975 (or later) to 2015. Additional details on the data are provided in Appendix A. 
Table C.IX: Welfare Costs of Temperature Risk: Different Temperature RISK

\begin{tabular}{lcc}
\hline \hline & {$\left[\tau_{T}=0\right]$} & {$\left[\tau_{T}=-0.00901\right]$} \\
\hline $\mathbb{E}(\hat{U})$ & 0.9708 & 0.9082 \\
$\Delta$ & - & $6.89 \%$ \\
\hline
\end{tabular}

Notes: This table reports the welfare costs of temperature shocks for the specification where temperature risk affects the macro economy differently in contrast to the benchmark model, i.e., as in Equation (C.5) with $\tau_{T}=-0.00901$. Welfare costs are defined as the percentage increase $\Delta>0$ in time-zero utility bundle units that the household should receive in order to be indifferent between living in an economy with full risk exposure (i.e., $\sigma_{T}, \sigma_{a}, \sigma_{g}>0$ ) and an economy without temperature effects. Temperature effects are eliminated by imposing $\tau_{T}=0$.

Table C.X: Long-Run Effects of Temperature Shocks: Different TemperATURE RISK

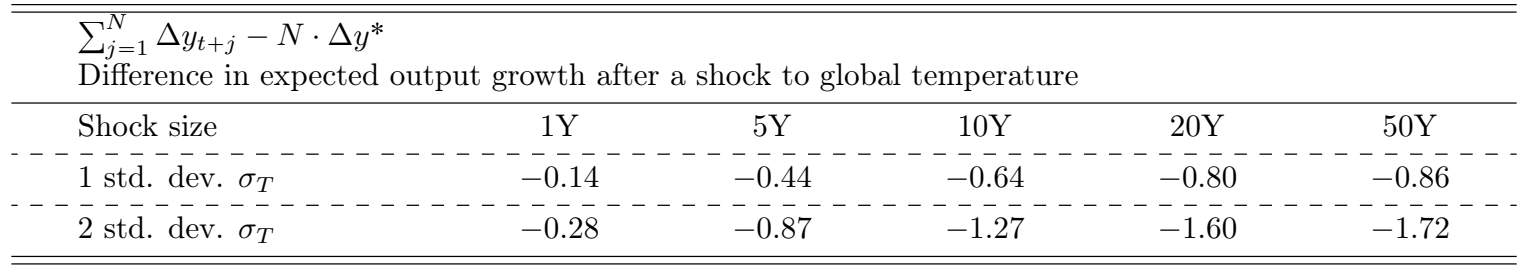

Notes: This table reports the cumulative change in output growth over $1,5,10,20$, and 50 years in percentage points after a temporary temperature shock for the specification where temperature risk affects the macro economy differently in contrast to the benchmark model, i.e., as in Equation (C.5) with $\tau_{T}=-0.00566$. The cumulative growth in an economy without such a shock is compared to that in an economy with shocks to temperature, $z_{t}$. Specifically, we report $\left(\sum_{j=1}^{N} \Delta y_{t+j}\right)-N \cdot \Delta y^{*}$ where $\Delta y_{t+j}$ is the log growth rate of total output, and $\Delta y^{*}$ is the steady state growth rate in the economy without a shock (i.e., with $\varepsilon_{T}=0$ ). For example, the entry -0.46 for a horizon of 5 years in the first row means that cumulative output growth over these 5 years has been 0.46 percentage points lower than it would have been without the temperature shock. The amount of lost output growth is reported for temperature shocks amounting to one and two standard deviations, i.e., to $0.12^{\circ} \mathrm{C}$ and $0.24^{\circ} \mathrm{C}$, respectively. 


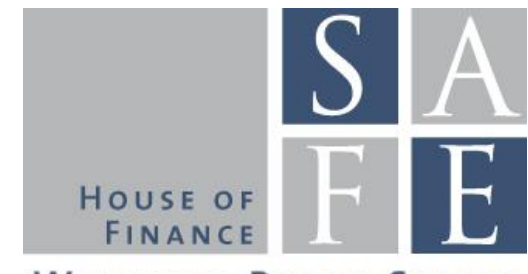

WORKING PAPER SERIES

\section{Recent Issues}

No. 187 Baptiste Massenot, Yuri Pettinicchi

No. 186 Nicole Branger, Paulo Rodrigues, Christian Schlag

No. 185 Patrick Grüning

No. 184 Tobias Tröger

No. 183 Joost Driessen, Theo E. Nijman, Zorka Simon

No. 182 Mario Bellia, Loriana Pelizzon, Marti G. Subrahmanyam, Jun Uno, Darya Yuferova

No. 181 Holger Kraft, Farina Weiss

No. 180 Tobias H. Tröger

No. 179 Tobias H. Tröger

No. 178 Matthias Goldmann

No.177 Michael Donadelli, Marcus Jüppner, Max Riedel, Christian Schlag

No. 176 Giuliano Curatola, llya Dergunov

No. 175 Reint Gropp, Deyan Radev
Can Firms see into the Future?

Survey evidence from Germany

Level and Slope of Volatility Smiles in LongRun Risk Models

Heterogeneity in the Internationalization of R\&D: Implications for Anomalies in Finance and Macroeconomics

Remarks on the German Regulation of Crowdfunding

The Missing Piece of the Puzzle: Liquidity Premiums in Inflation-Indexed Markets

Coming Early to the Party

Consumption-Portfolio Choice with Preferences for Cash

Why MREL Won't Help Much

Too Complex to Work: A Critical Assessment of the Bail-in Tool under the European Bank Recovery and Resolution Regime

United in Diversity? The Relationship between Monetary Policy and Banking Supervision in the Banking Union

Temperature Shocks and Welfare Costs

International Capital Markets with TimeVarying Preferences

International Banking Conglomerates and the Transmission of Lending Shocks across Borders 